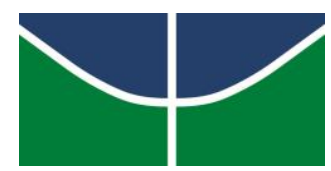

Universidade de Brasília - UnB Instituto de Ciências Humanas

Departamento de Geografia

Programa de Pós-Graduação em Geografia

\title{
SELEÇÃO DE ÁREAS PRIORITÁRIAS PARA REGULARIZAÇÃO FUNDIÁRIA NO ESTADO DA BAHIA
}

Luís Antônio dos Santos

Dissertação de Mestrado

Brasília- DF

Dezembro de 2016 


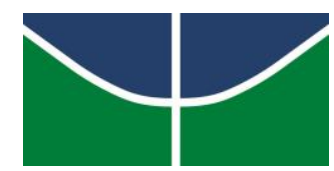

Universidade de Brasília - UnB Instituto de Ciências Humanas

Departamento de Geografia

Programa de Pós-Graduação em Geografia

\section{SELEÇÃO DE ÁREAS PRIORITÁRIAS PARA REGULARIZAÇAO FUNDIÁRIA NO ESTADO DA BAHIA}

Luís Antônio dos Santos

Orientador: Osmar Abílio de Carvalho Junior

Dissertação de Mestrado

Brasília- DF

Dezembro de 2016 


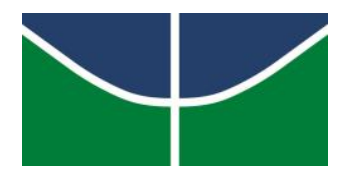

Universidade de Brasília - UnB

Instituto de Ciências Humanas

Departamento de Geografia

Programa de Pós-Graduação em Geografia

\title{
SELEÇÃO DE ÁREAS PRIORITÁRIAS PARA REGULARIZAÇAO FUNDIÁRIA NO ESTADO DA BAHIA
}

\author{
Luís Antônio dos Santos
}

Dissertação de Mestrado submetida ao Departamento de Geografia da Universidade de Brasília, como parte dos requisitos para a obtenção do Grau de Mestre em Geografia, área de concentração Gestão Ambiental e Territorial, opção Acadêmica.

Aprovado por:

Prof. Dr. Osmar Abílio de Carvalho Junior

(Orientador)

Prof. Dr. Edilson de Souza Bias

(Examinador Externo)

Prof. Dr. Renato Fontes Guimarães

(Examinador Interno)

Brasília-DF, 21 de dezembro de 2016. 


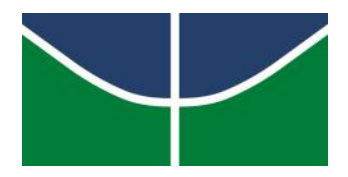

Universidade de Brasília - UnB

Instituto de Ciências Humanas

Departamento de Geografia

Programa de Pós-Graduação em Geografia

\section{FICHA CATALOGRÁFICA}

\section{SANTOS, LUÍS ANTÔNIO}

Seleção de Áreas Prioritárias para Regularização Fundiária. 42 p. 500 mm (UnB-IH/GEA, Mestre, Gestão Ambiental e Territorial, 2016).

Dissertação de Mestrado - Universidade de Brasília. Instituto de Ciências Humanas/Departamento de Geografia.

1. Regularização Fundiária

3. Análise multicritério
2. Georreferenciamento

4. Tomada de Decisão

\section{SELEÇÃO DE ÁREAS PRIORITÁRIAS PARA REGULARIZAÇÃO FUNDIÁRIA NO ESTADO DA BAHIA}

É Concedida à Universidade de Brasília permissão para reproduzir cópias desta dissertação e emprestar ou vender tais cópias somente para propósitos acadêmicos e científicos. O autor reserva outros direitos de publicação e nenhuma parte desta dissertação de mestrado pode ser reproduzida sem a autorização por escrito do autor. 
A presente dissertação foi elaborada no formato de artigo científico submetido a Finisterra Revista Portuguesa de Geografia conforme norma estabelecida pelo Programa de Pósgraduação em Geografia. 


\section{AGRADECIMENTOS}

O sustendo vem de Deus! Samech Alef Lamed.

Agradeço ao meu pai, em memória, a minha esposa pelo apoio e compreensão, a minha mãe e minha filha e a todos os meus amigos, que fizeram parte desta jornada.

Agradeço ao meu orientador: Professor Osmar Abílio de Carvalho Junior, sem o qual este trabalho não seria possível. Por sua orientação imprescindível, pela amizade e paciência.

Agradeço ao Instituto Nacional de Colonização e Reforma Agrária pelo apoio e oportunidade; em nome dos servidores, e amigos, Cláudio Roberto Siqueira, Edioni Gomes da Costa, José Leopoldo Ribeiro Viégas, Miguel Rosa e Judson Mattos.

Agradeço a Universidade de Brasília pelos momentos saborosos de convivência e busca do conhecimento.

Aos amigos Eduardo Marcelo Bezerra, Luiz Cláudio Berreta e ao Professor Valério A. P. Salomon, pelas contribuições. 


\section{RESUMO}

A questão da regularização fundiária é um importante problema brasileiro, onde o cadastramento das áreas, com expedição de títulos definitivos de propriedade, pode evitar a grilagem de terras, o êxodo rural e fortalecer a segurança jurídica e obtenção de créditos para as atividades agrícolas. A presente pesquisa possui como objetivo selecionar áreas prioritárias para regularização fundiária no Estado da Bahia (nordeste brasileiro), usando a análise multicritério. As variáveis municipais utilizadas foram: índice de desenvolvimento humano municipal, valor bruto de produção, número de fazendeiros sem os documentos da terra (posseiros), estabelecimentos familiares, declividade e propriedades cadastradas. No processamento dos dados foram utilizadas a Analytic Hierarchy Process (AHP) e a FuzzyAHP. O resultado final foi um mapa de síntese cartográfica proveniente da média aritmética desses modelos, contendo as seguintes classes de prioridade: alta, média, baixa e não prioritária. O método proposto determinou 128 municípios prioritários para ações imediatas de regularização fundiária com índice acima de 0,66 . Um recorte acima de 0,80 selecionou 22 municípios considerados como extremamente prioritário. Esses municípios prioritários formam um padrão espacial contínuo ao longo da depressão do rio São Francisco. A grande quantidade de posses e a baixa quantidade de áreas cadastradas no Estado da Bahia indica a importância de ações sistemáticas de georreferenciamento e regularização fundiária.

\footnotetext{
ABSTRACT

The issue of land regularization is an important problem in Brazil and the registration of areas, with the issuance of definitive propriety titles, can prevent land seizure, rural exodus, and strengthen legal security and credit for agricultural activities. This research aims to select priority areas for land regularization in the state of Bahia (Brazilian northeast) using a multicriteria analysis. The municipal variables used in the model were: municipal human development index, gross production value, number of farmers without land documents, proportion of family farms, slope, and registered properties. The data processing used were the Analytic Hierarchy Process (AHP) and fuzzy AHP methods. The final result was a cartographic synthesis map of the arithmetic rate of these models, containing the following priority classes: high, medium, low and non-priority. The proposed method determined 128 priority municipalities for immediate land regularization actions with a threshold value exceeding 0.66 and 22 extremely priority municipalities with a higher threshold than 0.80 . These priority municipalities have a continuous spatial pattern along the São Francisco river
} 
depression. The large number of possessions and the low number of registered areas in the State of Bahia indicates the importance of systematic actions for the spatial registration and the land regularization.

\section{RÉSUMÉ}

La question de la régularisation agraire est un important problème au Brésil, où l'enregistrement des zones, avec l'expédition des titres définitifs de propriété, peut éviter la saise des terres, l'exode rural et de renforcer la sécurité juridique et l'obtention de crédito pour les activités agricoles. La présente recherche possède comme objectif sélectionner des secteurs prioritaires pour régularisation agraire dans l'État de la Bahia (nord-est Brésilien), en utilisant l'analyse multi critère. Les variables municipales utilisées ont été: indice de développement humain municipal, valeur grossière de production, nombre d'agriculteurs sans les documents de la terre (possessionnels), établissements familiers, déclivité et propriétés cadastrées. Dans le traitement des données ils ont été utilisés à Analytic Hierarchy Process $(A H P)$ et à fuzzy $A H P$. Le résultat final a été une carte de synthèse cartographique provenant de la moyenne arithmétique de ces modèles, en contenant les suivantes classes de priorité: augmentation, moyenne, basse et non prioritaire. La méthode proposée a determine 128 villes prioritaires pour actions immédiates de régularisation agraire avec indice au-dessus de 0.66. Un découpage au-dessus de 0.80 a sélectionné 22 villes considérées comme extrêmement prioritaire. Ces villes prioritaires forment une norme spatiale continue au long de la dépression du fleuve San Francisco. La grande quantité de possessions et la basse quantité de secteurs cadastrés dana l'État de la Bahia indiquent l'importance d'actions systématiques de géoréférenciation et la régularisation agraire. 


\section{LISTA DE FIGURAS}

Figura 1 - Mapa dos Biomas e Referências de Localização .04

Figura 2 - Mapa das formas de relevo do Estado da Bahia .................................................06

Figura 3 - Padrão de Posse da Terra do Estado da Bahia 1549 - 2016 ...................................06

Figura 4 - Esquema da Árvore Hierárquica ou de Decisão ....................................................12

Figura 5 - Processo de Modelagem AHP e Fuzzy AHP ......................................................16

Figura 6 - Cartogramas das classes de prioridade, das variáveis .......................................17

Figura 7 - Matriz de Correlação com todas as variáveis ......................................................19

Figura 8 - Índice AHP/AHP-Fuzzy - Modelos: (a) M1, (b) M1F, (c) M2 e (d) M2F ............21

Figura 9 - Áreas prioritárias para regularização fundiária no estado da Bahia.......................22 


\section{LISTA DE QUADROS}

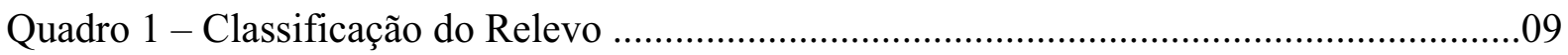

Quadro 2 - Escala Fundamental de Saaty .......................................................................... 12

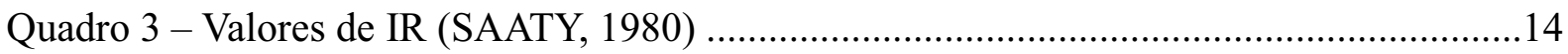

Quadro 4 - Equações para calcular a matriz A-Fuzzy …....................................................14

Quadro 5 - Matriz de correlação dos Índices .....................................................................18

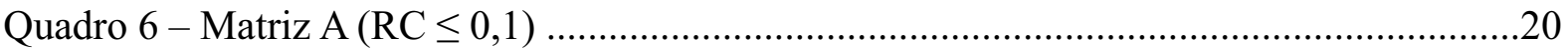

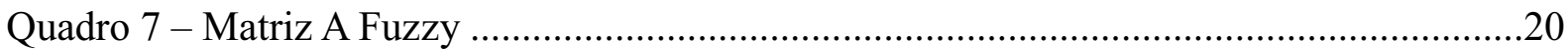




\section{LISTA DE ABREVIATURAS E SIGLAS}

ADME - Análise de Decisão Multicritério Espacial

AHP - Analytical Hierarchy Process (Processo Analítico Hierárquico)

$\mathrm{CF}$ - Constituição Federal

CNIR - Cadastro Nacional de Imóveis Rurais

CPRM - Serviço Geológico Brasileiro

DP - Declaração para Cadastro de Imóveis Rurais

EMBRAPA - Empresa Brasileira de Pesquisa Agropecuária

ESC - Terreno escarpado

Estab_F - Estabelecimentos Familiares

Estab_NF - Estabelecimentos não Familiares

F_OND - Terreno forte ondulado

G_IMPR - Número de propriedades - grandes Improdutivas

G_PROD - Número de propriedades - grandes produtivas.

IBGE - Instituto Brasileiro de Geografia e Estatística

IC - Índice de área cadastrada no SNCR

ID - Índice de Declividade

IEF - Índice de estabelecimentos familiares

INCRA - Instituto Nacional de Colonização e Reforma Agrária

IPos- Índice de posse

M_IMPR - Número de propriedades - médias improdutivas.

M_PROD - Número de propriedades - médias produtivas.

MCDM - Multiple Criteria Decision Method

MINI_FUN - Número de propriedades - minifúndios.

MONT - Terreno montanhoso

NASA - National Aeronautics and Space Administration

OND - Terreno ondulado

PAM - Pesquisa Agrícola Municipal

PLAN - Terreno plano

PNUD - Programa da Nações Unidas para o Desenvolvimento

POSSESJT - Número de posses à justo título

POSSESSO - Número de posses por simples ocupação

PROPPOSSES - Número de propriedades e posses

RF - Receita Federal 
S_OND - Terreno suave ondulado

SIG - Sistema de Informações Geográficas

SIGEF - Sistema de Gestão Fundiária

SIRGAS - Sistema de Referência Geocêntrico das Américas

SNCR - Sistema Nacional de Cadastro de Imóveis

SRTM - Space Shuttle Topographic Mission

SSD - Sistema de Suporte a Decisão

UMC - Unidade Municipal de Cadastro

VBP - Valor Bruto de Produção 


\section{SUMÁRIO}

1. INTRODUÇÃO

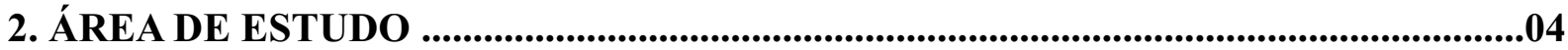

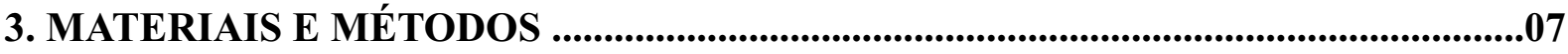

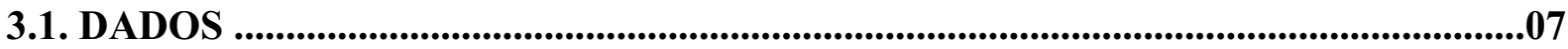

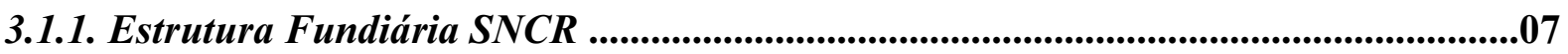

3.1.2. Estabelecimento Familiares e não Familiares .........................................................08

3.1.3. Classes de Declividade ...................................................................................................................08

3.1.4 - Índice de Desenvolvimento Humano Municipal (IDH-M) ...................................09

3.1.5 Valor Bruto de Produção (VBP) .............................................................................09

3.2. DETERMINAÇÃO E ANÁLISE DAS VARIÁVEIS............................................09

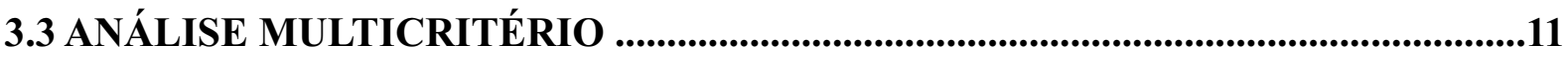

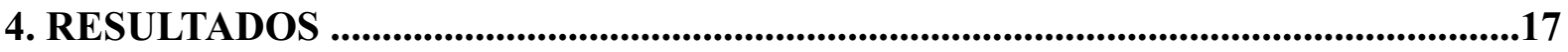

4.1. Resultados da Análise Exploratória das Variáveis.................................................17

4.2. Resultados da Modelagem AHP ..............................................................................19

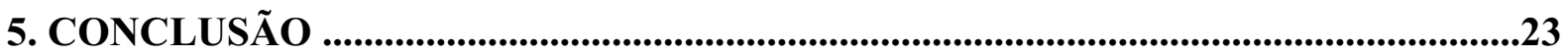

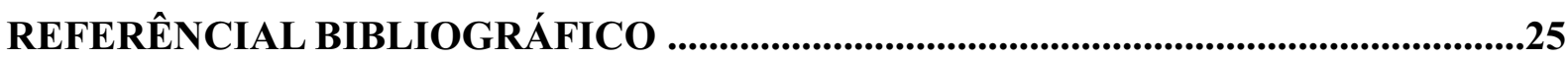




\section{INTRODUÇÃO}

Os Programas de Regularização Fundiária no Brasil fazem parte de uma série de medidas promovidas e fomentadas pelo Instituto Nacional de Colonização e Reforma Agrária (INCRA) em parceria com os estados e municípios, visando os seguintes propósitos: assegurar o pleno direito da função social da propriedade, garantir moradias, criar empregos, desenvolver políticas agrícolas, incentivo fiscal, credito rural e assistência técnica (CASSETTARI, 2015). Esses programas focam na permanência dos habitantes locais nas áreas atendidas e na segurança jurídica, expedindo títulos definitivos de propriedade para evitar a grilagem de terras e o êxodo rural (RAMBO, 2005). Complementarmente, a garantia de financiamentos bancários com taxas de juros mais acessíveis para o pequeno produtor rural possibilita mitigar os conflitos pela posse da terra e a pobreza extrema. Geralmente, estas medidas resultam nos seguintes benefícios: impulso ao desenvolvimento local e regional, melhora da qualidade de vida das famílias atendidas, aumento da renda mínima e inserção dos agricultores familiares ao sistema produtivo (REZENDE \& GUEDES, 2008; GUEDES \& REYDON, 2012). No entanto, os investimentos iniciais no desenvolvimento podem levar à dinâmica de concentração e monopólio no decorrer do tempo (HARVEY, 2014). Portanto, o monitoramento das terras deve ser um processo contínuo de gestão e ordenamento territorial (ANDRADE, 2013).

Conforme o Estatuto da Terra, Lei 4.504 (BRASIL, 1964), o Estado deve regularizar ou arrecadar as terras devolutas (CASSETTARI, 2015), basicamente áreas não registradas no cartório de registro de imóveis (MICHELINI, 2012), criando um estoque estratégico de terras que podem ser reordenadas de diversas formas, como por exemplo: criação de unidades de conservação ambiental e assentamento de reforma agrária. A questão da regularização fundiária e das terras devolutas é considerada desde 1976, através da Lei Federal 6.383 (BRASIL, 1976), mas continua sendo um problema atual. Segundo Medeiros (2012), a estrutura fundiária da região Nordeste, especialmente no Estado da Bahia, não houve praticamente nenhuma alteração entre o período de 1970 e 2006, data do último censo agropecuário, mantendo as desigualdades sociais e a perda de produtividade. Além das limitações físicas do Estado da Bahia, a desigualdade na repartição da terra e a falta da regularização fundiária (titulação) são importantes entraves para o desenvolvimento socioeconômico estadual (LEÃO, 1987).

Os processos de regularização, distribuição e redistribuição de terras aceleram a compra, venda e arrendamentos, aprimorando a dinâmica fundiária através do aumento do 
fluxo de negócios do mercado fundiário (DEININGER et al., 2014; NEWMAN et al., 2015). $\mathrm{O}$ registro da terra pelo proprietário rural inclui como possibilidade o penhor de colheitas pendentes e a hipoteca da propriedade para obtenção de crédito para as atividades agrícolas (MICHELINI, 2012). Além disso, o surgimento de empreendimentos mais produtivos gera empregos mais especializados com características distintas das anteriores, que modificam culturalmente a tradicional paisagem rural (DEININGER et al., 2014).

Além disso, as Diretrizes Voluntárias sobre a Governança Responsável da Terra, dos Recursos Pesqueiros e Florestais (FAO, 2012) recomendam que o Estado deva promover políticas públicas e, se necessário, criar legislação específica para reconhecer o direito da ocupação informal, estabelecer processos participativos e oferecer apoio técnico e jurídico para as comunidades e indivíduos afetados. Aproximadamente 400 mil imóveis do Estado da Bahia encontram-se classificados sob as formas de posse (INCRA, 2015): Posse a Justo Título, Posse por Simples Ocupação e, devido ao conceito de uso de imóvel rural, Propriedade e Posse (CASSETTARI, 2015).

A governança fundiária possui cinco áreas-chaves (NEWMAN et al., 2015): (a) direitos sobre a terra; (b) ordenamento do território; (c) gestão e tributação; (d) reforma agrária e; (e) prestação pública de informações geoespaciais sobre o território. Dessa forma, uma das etapas da regularização fundiária é o cadastramento georreferenciado dos imóveis rurais (KAUFMANN \& STEUDLER, 1998), através de ações discriminatórias (DIAS, 2007), chamadas de varredura, ou adjudicação sistemática (BOGAERTS \& ZEVENBERGEN, 2001). O cadastramento possibilita conhecer o território de forma precisa e completa, delimitando áreas passíveis de consolidação, separando a terra pública da terra privada, demarcando áreas sujeitas à remoção ou assentamento. O cenário ideal seria o país conhecer a totalidade das parcelas que compõem o seu território (SOTO, 2001; SOUZA, 2008; HASENACK, 2013). Consequentemente, a falta do cadastramento e regularização fundiária na escala nacional e a impossibilidade de se fazer essas ações para todo o território em curto prazo, devido a sua dimensão continental, torna a priorização de áreas uma etapa fundamental, incluindo a opção pelos mais pobres.

O estudo comparativo de tais áreas no campo geográfico utiliza-se de métodos estatísticos e matemáticos, sob os quais certos fatores são controlados e mantidos constantes, enquanto outros variam (CHORLEY \& HAGGETT, 1975; HARTSHORNE, 1978; SCHIER, 2003). A análise multicritério incorporada em um Sistema de Informação Geográfica (SIG) é uma ferramenta adequada para a prospecção espacial, que possui um caráter semiótico para a diferenciação de áreas (SCHIER, 2003). Essa abordagem permite aos tomadores de decisão 
formular problemas complexos em diversos níveis hierárquicos, podendo ponderar elementos contraditórios como, as diferenças regionais, socioeconômicas ou ambientais (COLLINS et al., 2001).

$\mathrm{Na}$ análise multicritério um modelo matemático muito utilizado é o Analytical Hierarchy Process (AHP) (SAATY, 1980, 2008, 2012). Vários estudos focam nos aspectos conceituas e axiomáticos do AHP (CRAWFORD \& WILLIANS, 1985; WANG \& ELHAG, 2006), enquanto outros na sua aplicação (SAATY, 1980, 2012). A decisão multicritério envolve um processo de múltiplos estágios: (a) a definição dos objetivos; (b) a escolha dos critérios para medir ou alcançar os objetivos; (c) a escolha das alternativas possíveis; (d) a atribuição ou ponderação dos pesos associados aos critérios escolhidos; (e) a aplicação de um algoritmo matemático para classificar as alternativas dentro dos parâmetros escolhidos (MOSADEGHI et al., 2015). A AHP foi utilizada na seleção de fazendas para a produção de energia solar e realocação de assentamentos na província de Konya na Turquia (UYAN, 2013; CAY \& UYAN, 2013). Outra abordagem para aumentar as possibilidades de julgamentos é o emprego da AHP-Fuzzy baseado na entropia de Shannon (SHANNON, 1949), que tem sido utilizada em diversos trabalhos, por exemplo, na análise de risco de usinas hidroelétricas (LINHARES et al., 2012) e no planejamento do uso da terra no Sudeste de Queensland, Austrália (MOSADEGHI et al. 2015). O presente trabalho possui como objetivo utilizar a análise multicritério no apoio à tomada de decisão para seleção de áreas prioritárias para regularização fundiária no Estado da Bahia, adotando uma combinação dos modelos matemáticos AHP e AHP-Fuzzy, em um ambiente de SIG. 


\section{2. ÁREA DE ESTUDO}

A área de estudo é o Estado da Bahia, com 417 municípios, contendo 564.693 quilômetros quadrados e população de 14 milhões de habitantes (IBGE, 2010), onde 4 milhões de habitantes vivem na mesorregião Metropolitana da capital Salvador. O Estado situa-se ao sul da região Nordeste, fazendo limite com oito Estados brasileiros e possuindo três biomas (Cerrado, Caatinga e Mata Atlântica), que caracterizam diferentes contextos físicos (relevo, chuva, vegetação), mas também, econômicos, sociais e culturais (fig. 1).

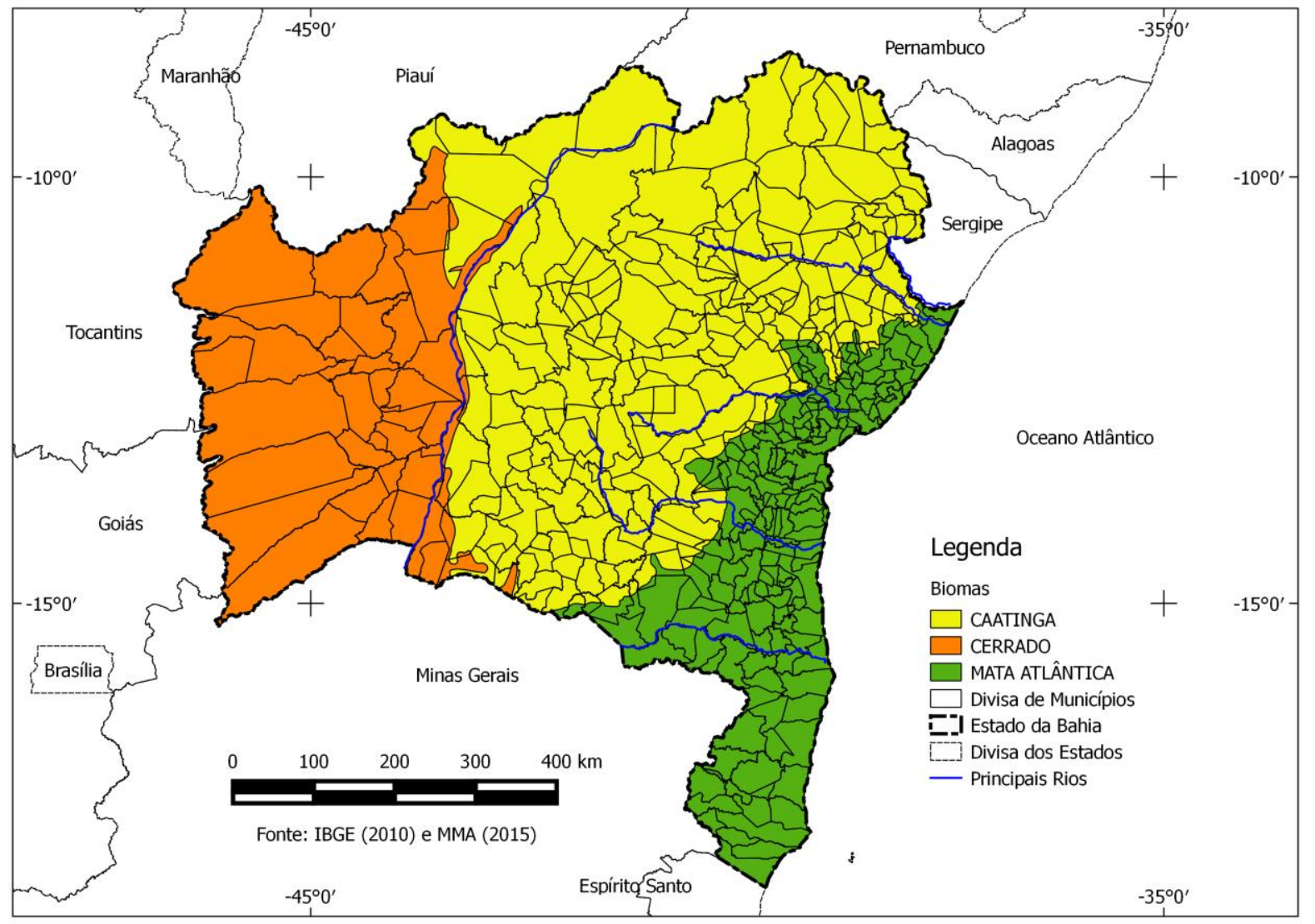

Fig. 1 - Mapa dos Biomas e Referências de Localização.

No Estado da Bahia predomina o clima tropical. Na Zona da Mata o regime de chuvas é mediterrâneo, com o máximo de precipitação ocorrendo nos meses de inverno, de março a setembro. Entre Salvador e Ilhéus a precipitação anual é superior a 2.600 milímetros (DIEZ, 2011), não existindo períodos secos. No interior da Zona da Mata o período seco é inferior a três meses. No Agreste (área de transição entre a Mata Atlântica e a Caatinga) predominam dois regimes pluviométricos, variando entre 500 e 1200 milímetros, ao norte o regime é mediterrâneo e ao sul o regime é considerado tropical, com o máximo de chuvas ocorrendo no verão. O período seco varia de três a seis meses. Na região da caatinga, o clima é semiárido e 
o regime é considerado tropical, com a máxima precipitação ocorrendo no verão, entre 400 e 800 milímetros, sendo que estação seca prolonga-se por quatro a dez meses, mas onde a precipitação é inferior a 600 milímetros, não existe um padrão regular de chuvas (LEÃO, 1987; DIEZ 2011). No extremo oeste, na região de Cerrado, as chuvas aumentam na direção da serra do Espigão Mestre, atingindo 1.000 milímetros anuais (DIEZ, 2011), onde estão localizadas as grandes áreas de produção de grãos.

O território da Bahia envolve partes do Planalto Central e Nordestino, com altitudes médias variando entre 300 e 1.000 metros acima do nível do mar (LEÃO, 1987) (fig. 2). A região da Chapada Diamantina, prolongamento da Serra do Espinhaço, divide as bacias hidrográficas do Leste e do Oeste. O rio São Francisco é o principal rio da bacia do Oeste, nasce no Estado de Minas Gerais e cruza a Bahia no sentido sul-norte. Na bacia do Leste existem vários rios importantes, mas o principal é o rio Paraguaçu, com 600 quilômetros de extensão, nasce na Chapada Diamantina e desagua na baía de Todos-os-Santos, integrando vários municípios do Recôncavo Baiano desde o início da ocupação do território (DIEZ, 2011; ANDRADE, 2013).

O processo de ocupação do Estado da Bahia começou com a chegada de Tomé de Souza, o primeiro governador do Brasil, em 1549, estabelecendo o Governo Central no Estado. Por volta de 1570 já se observava os efeitos espaciais da política colonial portuguesa (LEÃO, 1987). A distribuição dos engenhos e a expansão da cana de açúcar, pelo Recôncavo baiano, forçou a interiorização (LEÃO, 1987; ANDRADE, 2013). A evolução da divisão da terra até 1900 descreve o processo de ocupação do território (LEÃO, 1987). A região agrícola do oeste baiano foi incorporada ao Estado em 1827 e transformou-se a partir de 1990 em um eixo de expansão do agronegócio (OLIVEIRA et al., 2016, 2017), levando o Governo Federal a criar o plano de desenvolvimento Agropecuário do MATOPIBA (BRASIL, 2015).

A certificação dos imóveis Rurais (INCRA, 2016) evidencia um grande vazio cartográfico cadastral, principalmente na região central do Estado. Agravado pelas condições climáticas do semiárido e pela falta de regularização da documentação da terra. Dessa forma ainda persiste o dualismo Latifúndio-Minifúndio, onde o índice de Gini aumentou de 0,801 para 0,840 entre 1967 a 2006 (POCHMANN, 2015). Somado ao problema das posses, o Estado da Bahia possui em 2016 quase 600 mil imóveis com áreas abaixo de 4 módulos fiscais, que deverão ser georreferenciados segundo a Lei 10.267 (BRASIL, 2001) pelo INCRA, - a referida lei atribui ao INCRA a criação das diretrizes para o georreferenciamento dos imóveis rurais - somando quase 1 milhão de imóveis, como área conhecida, que precisarão ser regularizados (fig. 3). 


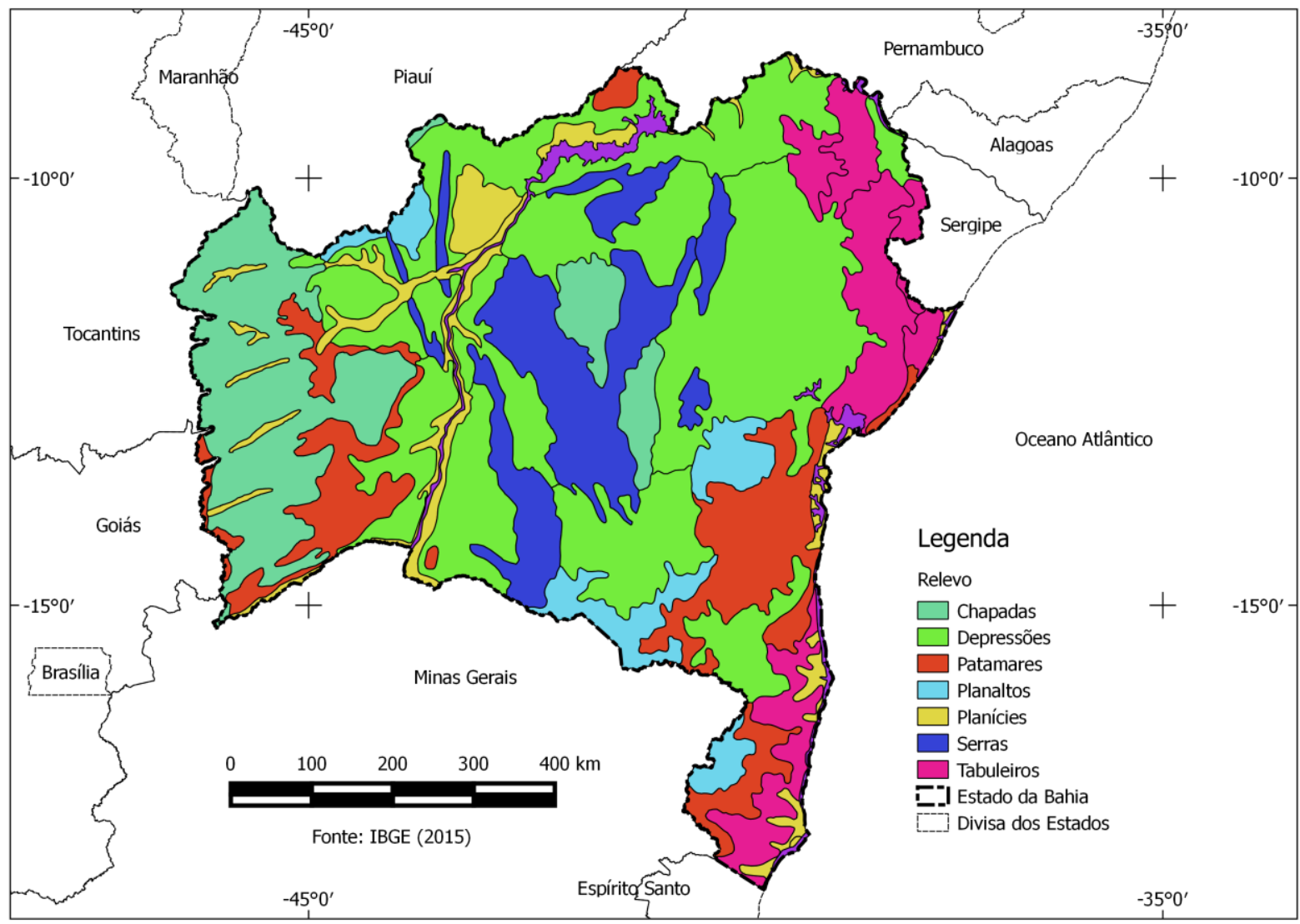

Fig. 2 - Mapa das formas de relevo do Estado da Bahia.

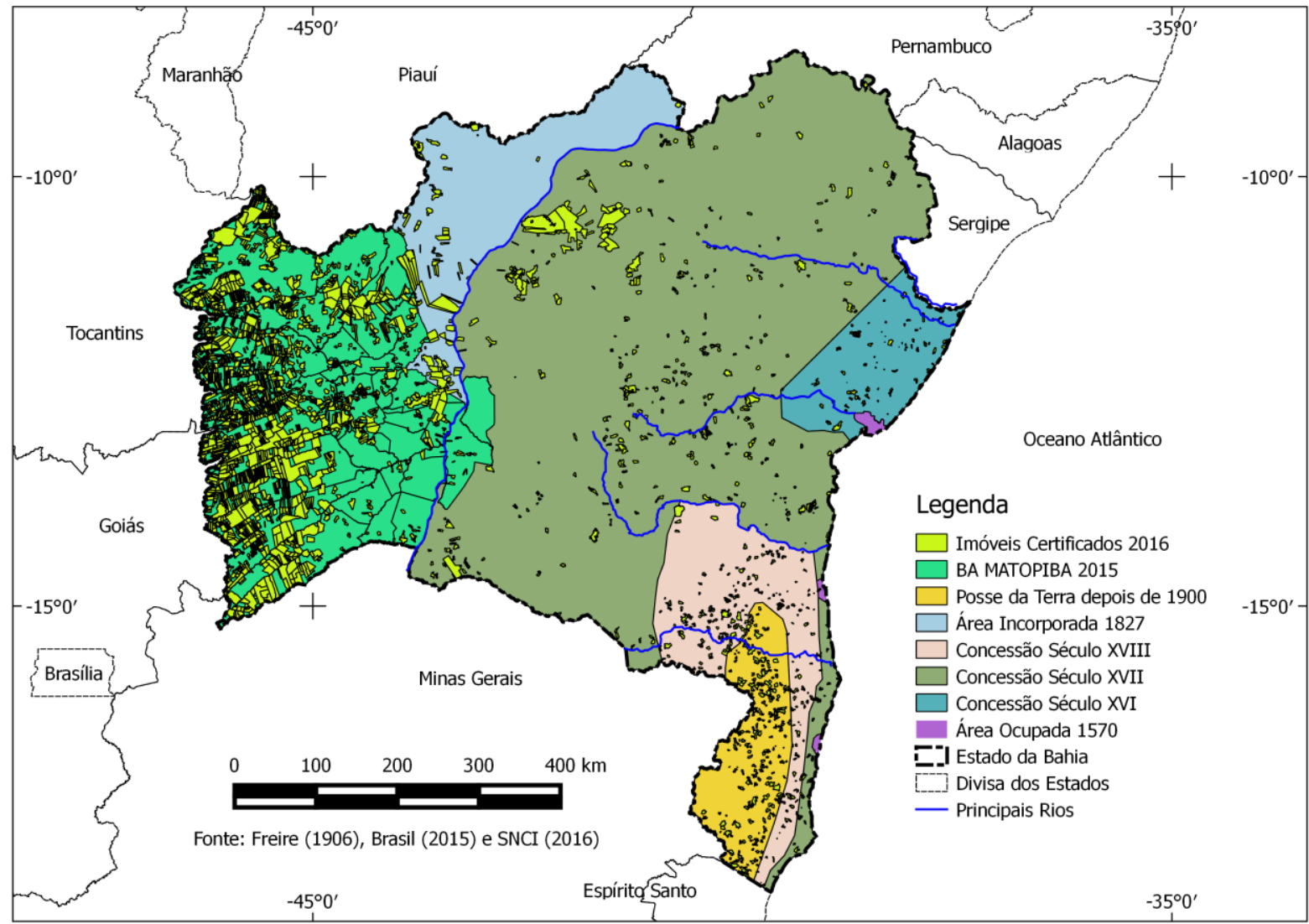

Fig. 3 - Padrão de Posse da Terra do Estado da Bahia no período 1549-2016. 


\section{MATERIAIS E MÉTODOS}

\subsection{DADOS}

No presente estudo foram utilizadas as seguintes variáveis: (a) estrutura fundiária (número de imóveis e área) (INCRA, 2015) (b) estabelecimento familiares e não familiares, imóveis abaixo de quatro módulos fiscais (IBGE, 2006); (c) área das classes de declividade (CPRM, 2016); (d) valor bruto de produção (em Mil R\$) proveniente da Pesquisa Agrícola Municipal (PAM) (IBGE, 2013); e (e) índice de Desenvolvimento Humano Municipal (IDHM) (PNUD, 2010). Os dados de entrada foram tabulados em uma matriz com 417 linhas por 31 colunas, incluindo os 4 índices calculados.

\subsubsection{Estrutura Fundiária SNCR}

O Cadastro Rural no Brasil surgiu a partir da Lei 4.504/64 (Estatuto da Terra) utiliza o conceito de Imóvel Rural: o prédio rústico, de área contínua qualquer que seja a sua localização que se destina à exploração extrativista agrícola, pecuária ou agroindustrial, quer através de planos públicos de valorização, quer através de iniciativa privada. Os imóveis rurais podem ser subdivididos em empresa rural e propriedade familiar. A empresa rural é o empreendimento de pessoa física ou jurídica, pública ou privada, que explore econômica e racionalmente o imóvel rural. A propriedade familiar é o imóvel rural que, direta e pessoalmente explorado pelo agricultor e sua família, lhes absorva toda a força de trabalho, garantindo-lhes a subsistência e o progresso social e econômico, e eventualmente contando com o trabalho ou a ajuda de terceiros.

O imóvel rural expressa a dimensão geométrica e a situação geográfica ou física, considerando as formas e as condições de aproveitamento econômico (CASSETTARI, 2015). O módulo rural é calculado para cada imóvel rural em separado e sua área reflete o tipo de exploração predominante na região. Desta forma, os imóveis rurais também podem ser classificados em: (a) Minifúndio: o imóvel rural de área menor a 1(um) módulo rural e com possibilidades inferiores a propriedade familiar; e (b) Latifúndio: o imóvel rural que mesmo não excedendo a área máxima de 600 módulos rurais (Latifúndio por extensão) é mantido inexplorado em relação às suas possibilidades físicas, econômicas e sociais.

Entretanto, a Constituição Federal (CF) de 1988 e a Lei 8.629/03 (Lei da Reforma Agrária) consideram outra classificação para os imóveis rurais a partir do conceito de módulo fiscal, que é a área mediana dos módulos rurais para cada Município. Portanto, essa lei estabelece as seguintes classes: (a) pequena propriedade: o imóvel rural com área 
compreendida entre 1(um) e 4 (quatro) módulos fiscais; (b) média propriedade: o imóvel rural com área superior a 4 (quatro) e até 15 (quinze) módulos fiscais; e (c) grande propriedade: o imóvel rural com área superior a 15 (quinze) módulos fiscais. Dessa forma, por analogia, imóveis menores que $1(\mathrm{um})$ e acima de 15 (quinze) módulos fiscais (Improdutivos) são considerados, tecnicamente, com minifúndios e latifúndios.

Os imóveis rurais também podem ser divididos em duas categorias, propriedade (Que possui título regularizado, expressando a posse e o domínio) e posse: Posses por Simples Ocupação (Ocupação mansa e pacífica), Posses a Justo Título (Que irradia boa-fé) e, devido a natureza de uso contínuo, a condição de sobreposição entre Propriedade e Posse.

O SNCR é um cadastro literal e declaratório, mas obrigatório para todos os imóveis Rurais. O cadastro era realizado através do preenchimento do formulário de Declaração para Cadastro de Imóveis Rurais (DP), nas Unidades Municipais de Cadastro (UMC), contendo informações sobre o imóvel (área e perímetro), sobre o uso e sobre o proprietário, ou detentor. Com a implantação do Cadastro Nacional de Imóveis Rurais (CNIR) (Em Evolução), o cadastro tornou-se eletrônico (DP Eletrônica) e as informações passam a ser cruzadas com os dados declaratórios do imposto de renda, da Receita Federal (RF). Entretanto, ainda não existe uma conexão efetiva entre os dados do SNCR e o Sistema de Gestão Fundiária (SIGEF) que, em virtude da lei 10.267, coleta informações espaciais dos imóveis rurais.

\subsubsection{Estabelecimento Familiares e não Familiares}

A Lei 11.326 (BRASIL, 2006) criou mais duas categorias, os Estabelecimentos Familiares e não Familiares, que são imóveis com área não superior a 4 módulos fiscais (Pequena Propriedade), mas com algumas características distintas, como: a utilização de mão de obra predominantemente familiar ou comunidades tradicionais. A referida lei concedeu

alguns benefícios a estas propriedades, mas infelizmente não tocou na questão da regularização fundiária.

\subsubsection{Classes de Declividade}

O mapa de declividade composto por seis classes de declividade conforme o critério da EMBRAPA (1979) (Quadro 1) foi obtido a partir do Serviço Geológico do Brasil (CPRM) sobre a Carta do Brasil ao Milionésimo (SC 23 - Rio São Francisco; SD 23 - Brasília; SC 24 - Aracajú; SD 24 - Salvador; e SE 24 - Rio Doce) (CPRM, 2016). O mapa da CPRM foi gerado utilizando o modelo digital de elevação da Space Shuttle Topographic Mission (SRTM) com resolução espacial de 90 metros (VAN ZYL, 2001). As classes de declividade 
foram vetorizadas e recortadas para cada município usando o programa Quantum GIS (GRASER, 2013). Além disso, o mapa da CPRM já desconsidera as áreas cobertas por água, facilitando o cálculo da Área Útil do Município.

Quadro 1 - Classificação do Relevo (EMBRA
\begin{tabular}{|cc|}
\hline Declividade & Discriminação do Relevo \\
\hline $0-3$ & Plano \\
$3-8$ & Suave Ondulado \\
$8-20$ & Ondulado \\
$20-45$ & Forte Ondulado \\
$45-75$ & Montanhoso \\
$>75$ & Escarpado \\
\hline
\end{tabular}

\subsection{4 - Índice de Desenvolvimento Humano Municipal (IDH-M)}

O IDH-M é uma medida de longo prazo que considera três dimensões: longevidade, educação e renda (PNUD, 2010). O índice varia de 0 e 1, quanto mais perto de 1 maior é o desenvolvimento humano. É considerado adequado para avaliar o estágio de desenvolvimento social dos municípios e pode ser usado para orientar políticas públicas.

\subsubsection{Valor Bruto de Produção (VBP)}

O valor bruto de produção (em Mil R\$) foi extraído do Sistema IBGE de Recuperação Automática (SIDRA), referentes a Pesquisa Agrícola Municipal (PAM) (IBGE, 2013). Os dados da VBP são obtidos através de entidades públicas e privadas, envolvendo produtores, técnicos ou órgão ligados aos setores de produção. É um sistema de informação que reflete a realidade econômica dos 5.565 municípios brasileiros.

\subsection{DETERMINAÇÃO E ANÁLISE DAS VARIÁVEIS}

$\mathrm{Na}$ análise das áreas prioritárias para a regulamentação fundiária foram estabelecidos seis critérios principais, compostos pelos atributos IDH-M e VBP somados de quatro índices formulados nessa pesquisa (posse, estabelecimento familiar, área cadastrada e declividade). A escolha das variáveis IDH-M e VBP procura refletir o que determina a Constituição Federal (CF), no seu artigo 186, quando trata a função social da propriedade, sob quatro aspectos: (a) aproveitamento racional; (b) utilização adequada dos recursos naturais; (c) observância das disposições que regulam as relações de trabalho; e (d) bem-estar do trabalhador. 
Os índices foram desenvolvidos para sintetizar a maior proporção de famílias e áreas presentes nos municípios com carência de cadastramento. A necessidade de aparto jurídico é restrita a categoria de posse, pois a propriedade particular já possui regularização fundiária. Dessa forma, é importante estabelecer um índice de quantidades de posseiros (incluindo posse por simples ocupação, posse a justo título e propriedade e posse) existente no município em relação ao total imóveis rurais. Esse índice permite estabelecer os municípios com maior demanda relativas de famílias para a aquisição da titulação de terras. O índice de posse (IPos) por município foi calculado considerando o número de posses (NPos) e o número de propriedades (NProp) pela seguinte equação:

$$
\text { IPos }=\text { NPos } /(\text { NPos }+ \text { NProp })
$$

Outro fator importante é quantificar os estabelecimentos familiares, que conforme o Censo Agropecuário de 2006 possui uma área não superior a 4 módulos físcais, sendo constituída principalmente por pequenos agricultores que necessitam prioridades para serem incluídos em programas de desenvolvimento local. Os imóveis abaixo de 4 módulos fiscais, segundo a Lei 10.267, são de responsabilidade do Governo Federal. O índice de estabelecimentos familiares (IEF) relaciona o número estabelecimentos familiares (NEF) e o número estabelecimentos não familiares (NENF), descrito pela equação:

$$
\mathrm{IEF}=\mathrm{NEF} /(\mathrm{NEF}+\mathrm{NENF})
$$

O índice de declividade (ID) estabelece a relação entre a soma das classes de declividade alta (fortemente ondulado, montanhoso e escarpado) (SDA) com a soma de todas as classes de declividade (SD). Este índice procura estabelecer áreas que não são de interesses para ações de regularização fundiária.

$$
\mathrm{ID}=\mathrm{SDA} / \mathrm{SD}
$$

O índice de área cadastrada (IC) estabelece a relação entre a área cadastra no SNCR (ASNCR) e a área do município (AM). Este índice permite estabelecer a proporção real do município já cadastrado:

$$
\mathrm{IC}=(\mathrm{AM}-\mathrm{ASNCR}) / \mathrm{AM}
$$


As variáveis por serem oriundas de diferentes fontes e dimensões foram colocados em uma mesma escala entre 0 e 1 , considerando a sua relação direta ou inversa com as áreas prioritárias para a regularização fundiária, adotando as equações 4 e 5 :

$$
\begin{aligned}
& \text { Direta }=\frac{\text { Valor_i }- \text { Valor_mínimo }}{\text { Valor_max }- \text { Valor_min }} \\
& \text { Inversa }=\frac{\text { Valor_max }- \text { Valor_i }}{\text { Valor_max }- \text { Valor_min }}
\end{aligned}
$$

Complementarmente, as variáveis selecionadas foram comparadas em uma matriz de correlação de Person entre todos os dados, utilizando o pacote Corrplot do Sistema Estatístico R (MURDOCH \& CHOW, 1996; FRIENDLY, 2002). A análise de correlação permite uma estimativa da relação entre as variáveis, que pode ser +1 ou -1 , quando todos os pontos estão sobre uma mesma reta, e zero, quando o ajustamento é tão pobre que o conhecimento de " $\mathrm{x}$ " em nada contribui sobre a predição de "y".

\subsection{ANÁLISE MULTICRITÉRIO}

O AHP é uma ferramenta com robustez matemática, muito útil e simples de usar. A AHP é recomendada em duas situações (BOLLOJU, 2001): (a) para dar suporte às alternativas de classificação sugeridas por um grupo de decisão ou um indivíduo específico; e (b) servir como Sistema de Suporte a Decisão (SSD). Esse método permite a comparação par a par dos elementos de decisão e a modelagem de problemas complexos em níveis hierárquicos (SALOMON, 1999; BOLLOJU, 2001; AKINCI et al., 2013). Na presente pesquisa, a seguinte árvore hierárquica foi estruturada: (a) no topo encontra-se a função objetivo que é a obtenção das Áreas Prioritárias para Regularização Fundiária; (b) no meio encontram-se os critérios do problema que precisarão ser ponderados; e (c) na base as alternativas (municípios) de decisão (fig. 4).

Na solução do modelo AHP devem ser observados sete passos: (a) construção da matriz de comparação par a par, matriz A; (b) cálculo do autovetor principal, matriz W; (c) cálculo do máximo autovalor ( $(\lambda \max )$; (d) cálculo do índice de consistência (IC); (e) cálculo do índice de aleatoriedade ou randômico (IR); (f) cálculo da razão de consistência (RC) e; (g) eventual realização de uma nova matriz de comparação, se (RC) for superior a 0,01 (SILVA et al, 2004). 
A partir do modelo hierárquico, constrói-se a matriz A quadrada de comparação pareada cuja ordem é igual ao número de critérios (n). Na construção da matriz A adota como referência a escala contínua de nove pontos proposta por Saaty $(1980)$ com valores $(1 / 9,9)$ (Quadro 2).

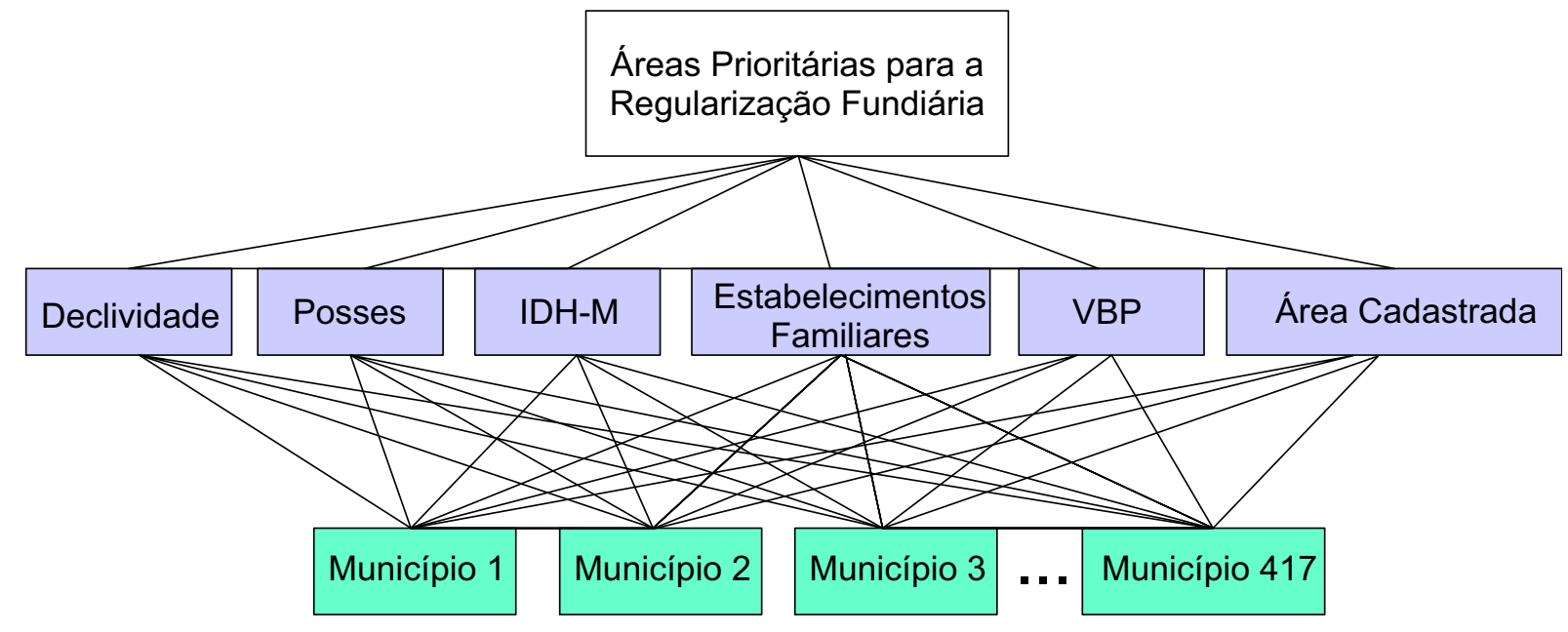

Fig. 4 - Esquema da Árvore Hierárquica ou de Decisão para o estudo de áreas prioritárias para a regularização fundiária

Quadro 2 - Escala Fundamental de Saaty (SAATY, 1980)

\begin{tabular}{|ll|}
\hline Valores numéricos de $\mathbf{a}_{\mathbf{i j}}$ & \multicolumn{1}{c|}{ Definição } \\
\hline 1 & Importância igual entre $\mathrm{i}$ e $\mathrm{j}$ \\
3 & Importância moderada de i sobre j \\
7 & Importância grande de i sobre j \\
9 & Importância muito grande de i sobre j \\
$2,4,6,8$ & Importância extrema de i sobre j \\
\hline
\end{tabular}

O método AHP permite determinar os pesos de todos os critérios, considerando matriz A (i x j) (eq. 6), onde $a_{i j}$ indica quanto a variável “i” é mais importante que a variável “j”, sendo que para todo "i" e “j” é necessário que $\mathrm{a}_{\mathrm{ii}}=1$ e $\mathrm{a}_{\mathrm{ij}}=1 / \mathrm{a}_{\mathrm{ji}}$ (eq. 6).

$$
A=\left[\begin{array}{ccc}
1 & a_{12} \ldots & a_{1 n} \\
\frac{1}{a_{21}} & 1 \ldots & a_{2 n} \\
\frac{1}{a_{n 1}} & \frac{1}{a_{n 2}} & 1
\end{array}\right]
$$


Onde

$$
\mathrm{a}_{\mathrm{ij}}=\frac{1}{\mathrm{a}_{\mathrm{ji}}} \forall \mathrm{i}, \mathrm{j}=1,2 \ldots, \mathrm{n}
$$

Depois cada valor da coluna $\mathrm{j}$ é dividido pela soma total dos valores da coluna j. O total desses valores para cada coluna resulta na nova matriz normalizada Aw.

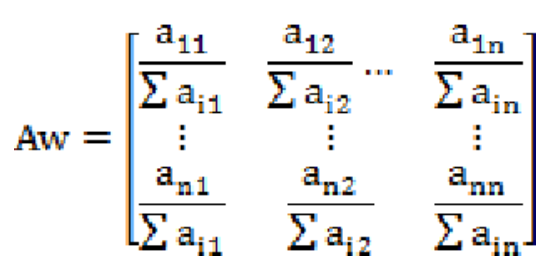

$\mathrm{O}$ vector $\mathrm{W}$ contendo o peso de cada critério é calculado como a média da soma dos valores da linha i da matriz Aw:

$$
W=\left[\begin{array}{c}
c_{1} \\
n \\
\vdots \\
c_{n} \\
n
\end{array}\right]=\left[\begin{array}{ccc}
\frac{a_{11}}{\sum a_{i 1}}+ & \frac{a_{12}}{\sum a_{i 2}} \ldots+ & \frac{a_{1 n}}{\sum a_{i n}} \\
\vdots & \vdots & \vdots \\
\frac{a_{n 1}}{\sum a_{i 1}}+ & \frac{a_{n 2}}{\sum a_{i 2}} \ldots+ & \frac{a_{n n}}{\sum a_{i n}}
\end{array}\right]
$$

A Razão de Consistência (RC) da comparação pareada indica a probabilidade de os valores calculados serem gerados aleatoriamente, efetuando a partir da divisão entre o Índice de Consistência ou (IC) e o Índice Randômico (IR) (eq. 10). O IC é calculado pelo máximo autovalor $(\lambda \max )$ da matriz A. Os valores do IR são estimados a partir do número de variáveis (N) (Saaty, 1980, 2008) (Quadro 3). Caso o RC esteja acima de 0,01 recomenda-se que seja feita uma nova rodada de comparação baseada em novos julgamentos. $\mathrm{Se} \mathrm{RC} \leq 0,01$ o grau de coerência é satisfatório, em contraposição se $\mathrm{RC}>0,01$ existem inconsistências graves.

$$
\mathrm{RC}=\frac{\mathrm{IC}}{\mathrm{IR}}
$$

Onde

$$
\text { IC }=\frac{\lambda \max -\mathrm{n}}{\mathrm{n}-1}
$$




$$
\begin{aligned}
\lambda \max & =\frac{1}{n} \sum_{\mathrm{i}=1}^{\mathrm{n}} \frac{\mathrm{A} \times \mathrm{W}}{\mathrm{W}_{\mathrm{i}}} \\
\mathrm{AxW} & =\left[\begin{array}{ccc}
1 & \mathrm{a}_{12} \ldots & \mathrm{a}_{1 \mathrm{n}} \\
\frac{1}{a_{21}} & 1 \ldots & \mathrm{a}_{2 \mathrm{n}} \\
\ldots & \ldots & \ldots \\
\frac{1}{a_{\mathrm{n} 1}} & \frac{1}{a_{\mathrm{n} 2}} & 1
\end{array}\right] \times\left[\begin{array}{c}
\frac{\mathrm{c}_{1}}{\mathrm{n}} \\
\vdots \\
\frac{\mathrm{c}_{\mathrm{n}}}{\mathrm{n}}
\end{array}\right]
\end{aligned}
$$

Quadro 3 - Valores de IR (SAATY, 1980)

\begin{tabular}{|c|c|c|c|c|c|c|c|c|c|}
\hline $\mathbf{n}$ & $\mathbf{1}$ & $\mathbf{2}$ & $\mathbf{3}$ & $\mathbf{4}$ & $\mathbf{5}$ & $\mathbf{6}$ & $\mathbf{7}$ & $\mathbf{8}$ & $\mathbf{9}$ \\
\hline $\mathrm{RI}$ & 0,00 & 0,00 & 0,58 & 0,90 & 1,12 & 1,24 & 1,41 & 1,45 & 1,49 \\
\hline
\end{tabular}

Várias simulações representativas da matriz A foram realizadas considerando o índice de posse em todos os julgamentos como a variável mais importante e adotando a que apresentou a menor RC. Além disso, efetuou-se a troca de posição dos coeficientes calculados no ordenamento da função objetivo, para realizar a análise de sensibilidade.

A lógica fuzzy foi utilizada para ampliar as simulações e por considerar as imprecisões e ambiguidades no processo de decisão, aumentando as possibilidades de soluções (LINHARES et al., 2012; MOSADEGHI et al., 2015). O método FAHP baseia-se na definição de critérios e alternativas da escolha que serão analisadas e hierarquizadas. Uma nova matriz A-Fuzzy é elaborada considerando os valores "aij” proveniente da matriz A do julgamento AHP e o grau de imprecisão do julgamento $(\alpha)$. O cálculo é realizado de forma distinta para as seguintes condições: (a) parte triangular superior da matriz; (b) parte triangular inferior da matriz; (c) diagonal; e (d) quando o valor for igual a nove, valor máximo na escala de Saaty (Quadro 4).

Quadro 4 - Equações para calcular a matriz A-Fuzzy considerando sua posição na matriz A.

\begin{tabular}{|l|cc|}
\hline \multicolumn{1}{|c|}{ Posição da matriz } & \multicolumn{2}{|c|}{ Equação a ser adotada } \\
\hline $\begin{array}{l}\text { Parte triangular superior da matriz } \\
(\mathrm{i} \text { é diferente de } \mathrm{j} \text { e } \mathrm{i}<\mathrm{j} .\end{array}$ & $\left(\mathrm{a}_{\mathrm{ij}}-\alpha, \mathrm{a}_{\mathrm{ij}}, \mathrm{a}_{\mathrm{ij}}+\alpha\right)$ \\
\hline $\begin{array}{l}\text { Parte triangular inferior da matriz } \\
\text { (j é diferente de } \mathrm{i} \text { e } \mathrm{j}<\mathrm{i} .\end{array}$ & $\left(1 /\left(\mathrm{a}_{\mathrm{ij}}+\alpha\right), 1 / \mathrm{a}_{\mathrm{ij}}, 1 /\left(\mathrm{a}_{\mathrm{ij}}-\alpha\right)\right)$ \\
\hline Diagonal $(\mathrm{i}=\mathrm{j})$ & $(1 /(1+\alpha), 1,1+\alpha)$ \\
\hline Valor $\mathrm{a}_{\mathrm{ij}}$ for igual a 9 & $(9-\alpha, 9,9)$ \\
\hline
\end{tabular}


Nesse trabalho foi considerado o número triangular fuzzy $(\alpha)$ igual a 0,5 de acordo com as seguintes equações (PACHECO, 2007):

$$
\begin{aligned}
& \mathrm{A} \alpha \mathrm{a}-1=(\mathrm{b} 2-\mathrm{b} 1) \alpha+\mathrm{b} 1 \text { (A1, B1, C1, D1, E1 e F1) } \\
& \mathrm{A} \alpha \mathrm{a}+1=-(\mathrm{b} 3-\mathrm{b} 2) \alpha+\mathrm{b} 3(\mathbf{A 3}, \mathrm{B3}, \mathrm{C3}, \mathrm{D3}, \mathbf{E 3}, \mathbf{e ~ F 3})
\end{aligned}
$$

Onde b1 é “ $\mathrm{a}_{\mathrm{ij}}+\alpha$ ”, b2 é $\mathrm{a}_{\mathrm{ij}}$ e b3 é " $\mathrm{a}_{\mathrm{ij}}-\alpha$ ".

$\mathrm{O}$ cálculo dos pesos considerou o vetor de frequência relativa (f) e a formulação da entropia de Shannon (H) (SHANNON, 1949; MON et al., 1994):

$$
\begin{aligned}
f=\left[\begin{array}{c}
f_{1} \\
\vdots \\
f_{n}
\end{array}\right]=\left[\begin{array}{ccc}
\frac{a_{11}}{\sum a_{i 1}} & \frac{a_{12}}{\sum a_{i 2}} \ldots & \frac{a_{1 n}}{\sum a_{i n}} \\
\vdots & \vdots & \vdots \\
\frac{a_{n 1}}{\sum a_{i 1}} & \frac{a_{n 2}}{\sum a_{i 2}} \ldots & \frac{a_{n n}}{\sum a_{i n}}
\end{array}\right] \\
H_{1}=-\sum_{j-1}^{n}\left(f_{1 j}\right) \log _{2}\left(f_{1 j}\right) \\
H_{2}=-\sum_{j-1}^{n}\left(f_{2 j}\right) \log _{2}\left(f_{2 j}\right) \\
H_{n}=-\sum_{j-1}^{n}\left(f_{n j}\right) \log _{2}\left(f_{n j}\right)
\end{aligned}
$$

Na presente pesquisa, o processo de modelagem foi realizado em cinco etapas: (a) as variáveis IPos, IC, IDH-M, VBP, IEF e ID foram ordenadas segundo a função M1 (eq. 20); (b) cálculo dos pesos w1, w2, w3, w4 e w5 através da AHP (Matriz A5x5); (c) estabelecimento de nova função M2, mantendo a Posse (IPos) constante (eq. 21) e os demais pesos trocados visando uma nova configuração de prioridades das variáveis ; (d) aplicação da lógica fuzzy para calcular novos valores para os pesos, mantendo os mesmos ordenamentos estabelecidos nas funções dos itens "a" e "c" produzindo mais duas possibilidades de solução M1F e M2F (eq. 22 e 23); (e) emprego do operador WLC (Weighted Linear Combination - WLC) (JIANG \& EASTMAN, 2000), para o cálculo dos índices de prioridade para cada modelo utilizado; e (f) espacialização dos resultados em quatro classes (fig. 5). 


$$
\begin{aligned}
& \text { M1 }=w 1 \times \text { IPos }+ \text { w2 } x \text { IC + w3 x IDH_M + w4 x IEF+ w5 x ID + w6 x VBP (eq. 23) } \\
& \text { M2 = w1 x IPos + w3 x IC + w2 x IDH_M + w5 x IEF+ w6 x ID + w4 x VBP (eq. 23) }
\end{aligned}
$$

$\mathrm{M} 1 \mathrm{~F}=\mathrm{wf1} \times \mathrm{IPos}+\mathrm{wf2} \times \mathrm{IC}+\mathrm{wf3} \times \mathrm{IDH} \_\mathrm{M}+\mathrm{wf4} \times \mathrm{IEF}+\mathrm{wf5} \mathrm{x}$ ID + wf6 x VBP (eq. 25) $\mathrm{M} 2 \mathrm{~F}=\mathrm{wf1} \times \mathrm{IPos}+\mathrm{wf3} \times \mathrm{IC}+\mathrm{wf2} \times \mathrm{IDH} \_\mathrm{M}+\mathrm{wf5} \times \mathrm{IEF}+\mathrm{wf6} \times \mathrm{ID}+\mathrm{wf} 4 \mathrm{x}$ VBP (eq. 26)

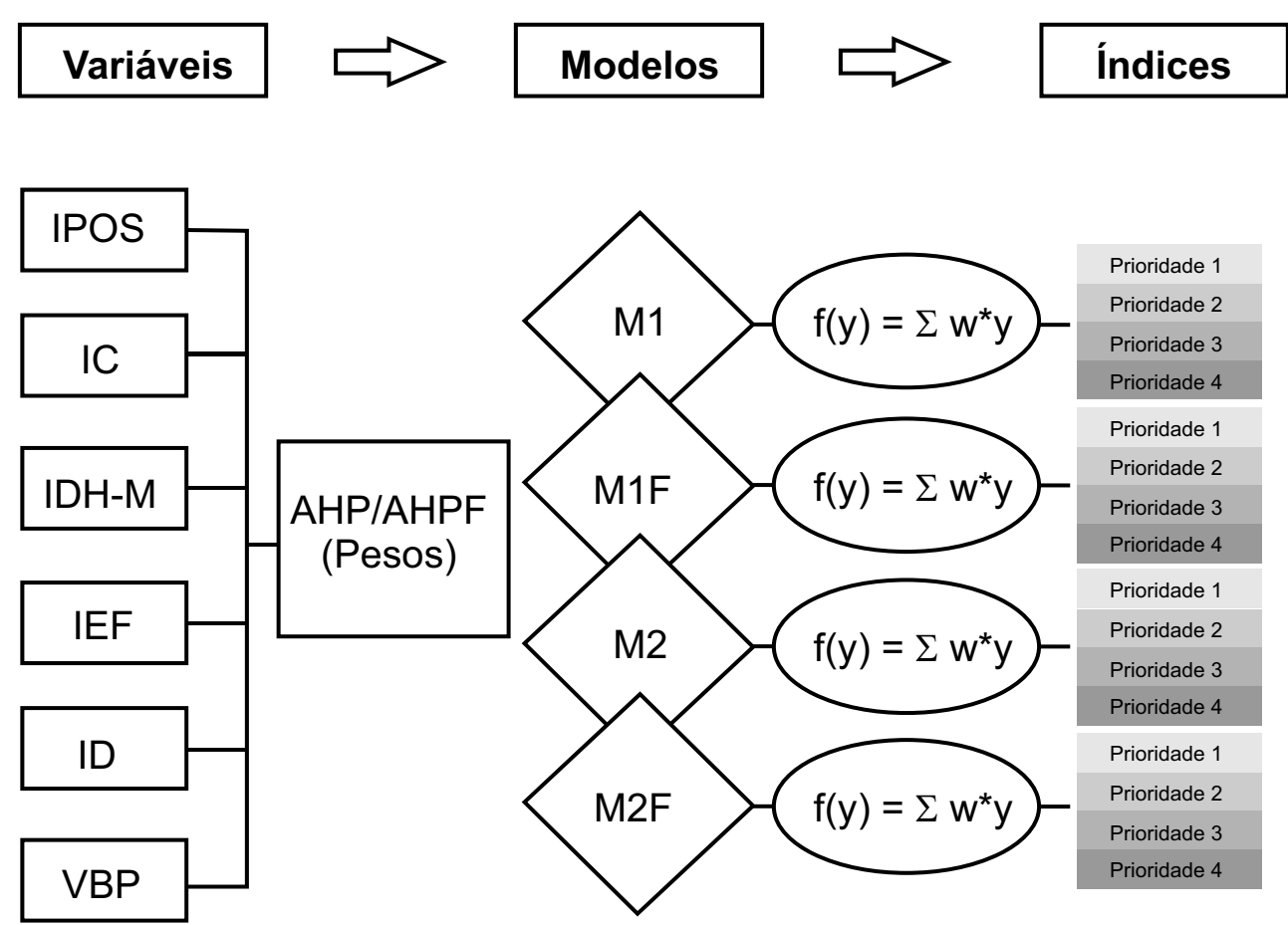

Fig. 5 - Processo de Modelagem AHP e Fuzzy AHP para seleção de áreas prioritárias para regularização fundiária no estado da Bahia. 


\section{RESULTADOS}

\subsection{RESULTADOS DA ANÁLISE EXPLORATÓRIA DAS VARIÁVEIS}

A Figura 6 demonstra os mapas de prioridade das variáveis normalizadas (eq.4 e eq.5) utilizadas na análise multicritério: IPos, IC, IDH-M, IEF, ID e VBP. Os mapas apresentam quatro classes de acordo com a Organização das Nações Unidas para a Alimentação e a Agricultura (FAO, 1976, SMYTH \& DUMANSKI, 1993): Não Prioritária; Prioridade Baixa; Prioridade Média e Prioridade Alta. As variáveis IDH-M, ID e VBP adotam os valores inversamente proporcionais para o estabelecimento das classes de prioridade. Nesses índices invertidos, quanto mais alto for o índice menor é a sua prioridade.
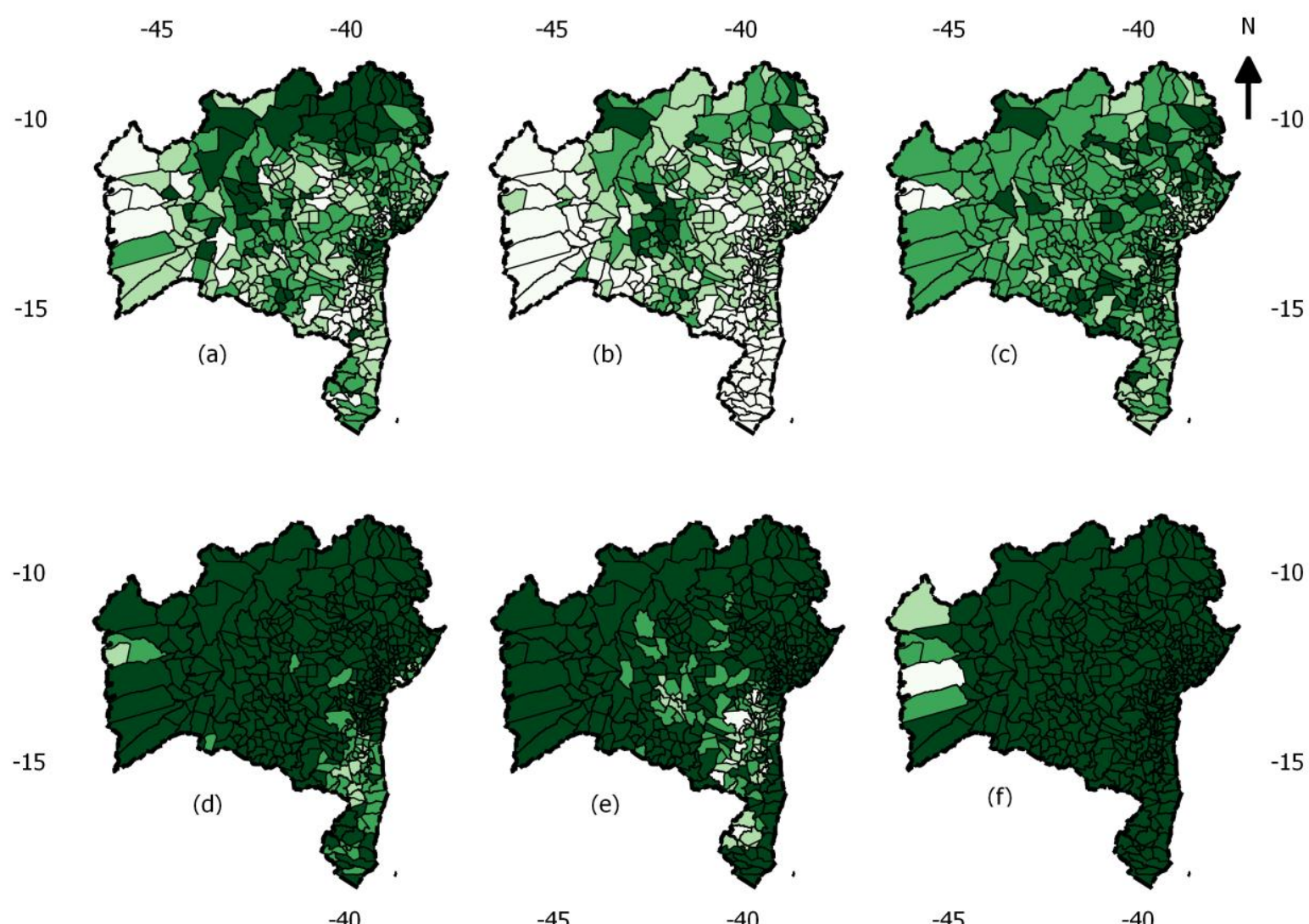

Legenda
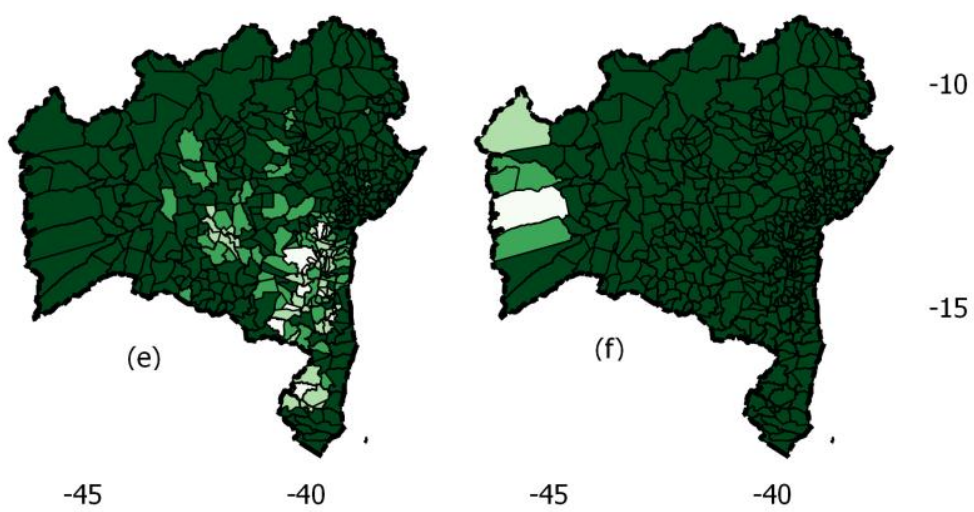

$\square$ Não Prioritária $\square$ Prioridade Baixa

Prioridade Média

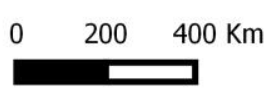

Datum: SIRGAS 2000

Fig. 6 - Cartogramas das classes de prioridade para regularização fundiária no Estado da

Bahia das seguintes variáveis municipais: (a) índice de posse (IPos), (b) índice de área cadastrada (IC), (c) índice de desenvolvimento humano municipal (IDH-M), (d) índice de estabelecimento familiares (IEF), (e) índice de declividade e

(f) valor bruto de produção (VBP). 
Os municípios com alta prioridade da variável IPos apresentam a maior concentração no extremo norte do Estado. As áreas mais desenvolvidas no Oeste, Sul e próximo a cidade de Salvador apresentam os melhores índices de cadastramento e consequentemente a menor prioridade. O IDHM é o índice que apresenta a distribuição mais heterogênea, havendo um predomínio da classe de prioridade média. Os índices IEF, ID e VBP apresentam um predomínio de áreas prioritárias com exceção de alguns municípios localizados no Oeste e Sul do Estado da Bahia.

A Figura 7 demonstra a matriz de correção entre todo o conjunto de dados levantados: estrutura fundiária (número e área dos imóveis), estabelecimentos familiares e não familiares, área das classes de declividade, IDH-M e índices calculados. A matriz de correlação demostra que as informações disponíveis de áreas cadastradas no SNCR ocorrem predominantemente nas áreas planas, suave onduladas e onduladas. Os Estabelecimentos Familiares estão correlacionados com as posses por simples ocupação e com os minifúndios e de acordo com o Estatuto da Terra deveriam ser objetos de Reordenamento Territorial ou Reforma Agrária.

O Quadro 5 demonstra uma baixa correlação entre as variáveis utilizadas na AHP, sendo adequada para a aplicação do modelo. Uma das exigências da AHP é a não correlação entre as variáveis.

Quadro 5 - Matriz de correlação entre os índices: posses (IPOS), índice de desenvolvimento humano municipal (IDHM), estabelecimentos familiares (IEF), declividade (ID), cadastro (IC) e valor bruto de produção (VBP).

\begin{tabular}{|c|c|c|c|c|c|c|}
\hline & IPOS & IDHM & IEF & ID & IC & VBP \\
\hline IPOS & 1 & $-0,17$ & 0,34 & $-0,16$ & 0,36 & $-0,17$ \\
\hline IDH-M & $-0,17$ & 1 & $-0,17$ & $-0,07$ & $-0,18$ & 0,06 \\
\hline IEF & 0,34 & $-0,17$ & 1 & $-0,29$ & 0,38 & $-0,19$ \\
\hline ID & $-0,16$ & $-0,07$ & $-0,29$ & 1 & $-0,17$ & 0,15 \\
\hline IC & 0,36 & $-0,18$ & 0,38 & $-0,17$ & 1 & $-0,34$ \\
\hline VBP & $-0,17$ & 0,06 & $-0,19$ & 0,15 & $-0,34$ & 1 \\
\hline
\end{tabular}




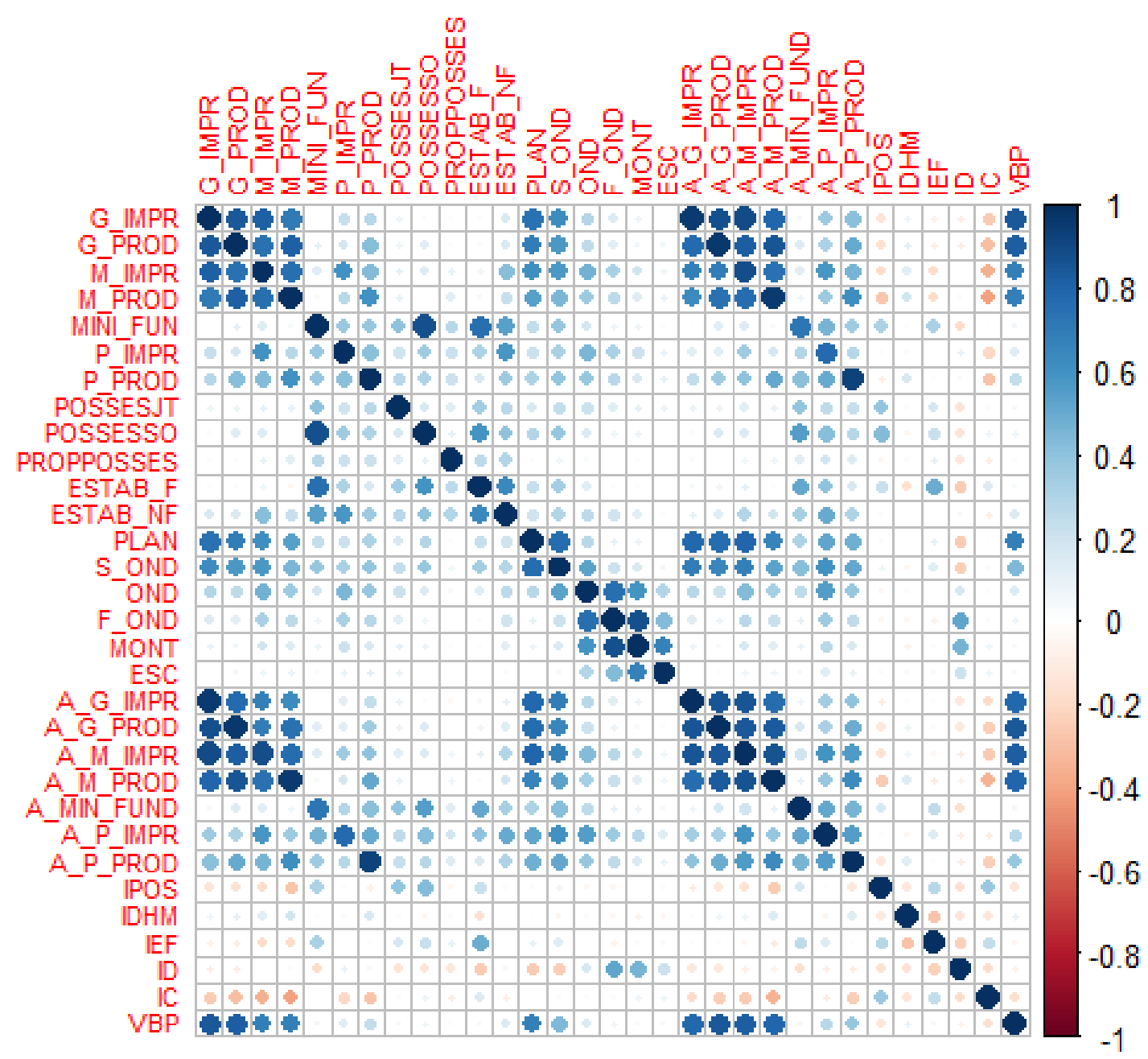

Fig. 7 - Matriz de correlação entre as seguintes variáveis: número das propriedades: grandes improdutivas (G_IMPR), grandes produtivas (G_PROD), médias improdutivas (M_IMPR), médias produtivas (M_PROD), minifúndios (MNI_FUN), pequenas improdutivas ( $\overline{\mathrm{P}}$ IMPR), pequenas produtivas (P_PROD), posses a justo título (POSSESJT), posses por simples ocupação (POSSESSO), sobreposição de propriedades e posses (PROPPOSSES), estabelecimentos familiares (ESTAB_F) e estabelecimentos não familiares (ESTAB_NF);

soma das áreas por classes de declividade: plana (PLAN), suave ondulada (S_OND), ondulada (OND), fortemente ondulada (F_OND), montanhoso (MONT) e escarpado ESC); área das propriedades: grandes improdutivas (A_G_IMPR), grandes produtivas

(A_G_PROD), médias improdutivas (A_M_IMPR), médias produtivas (M_PROD), minifúndios (A_MNI_FUN), pequenas improdutivas (A_P_IMPR), pequenas produtivas

(A_P_PROD); índices: posses (IPOS), índice de desenvolvimento humano municipal (IDHM), estabelecimentos familiares (IEF), declividade (ID), cadastro (IC) e valor bruto de produção (VBP).

\subsection{RESULTADOS DA MODELAGEM AHP}

O Quadro 6 apresenta a simulação (ou julgamento) da matriz A que apresentou o menor $\mathrm{RC}(\mathrm{RC} \leq 0,01)$. O Quadro 7 demonstra o resultado do emprego da lógica fuzzy utilizando como base a matriz $\mathrm{A}$, o $\alpha$-cut $=0,5$ e as equações 14 e 15 . A pesos da matriz A fuzzy foram calculados através da entropia de Shannon. 
Quadro 6 - Matriz A: posses (IPOS), índice de desenvolvimento humano municipal (IDHM), estabelecimentos familiares (IEF), declividade (ID), cadastro (IC) e valor bruto de produção (VBP).

\begin{tabular}{|c|c|c|c|c|c|c|}
\hline & IPos & IC & IDH-M & IEF & ID & VBP \\
\hline IPos & 1 & 1 & 2 & 4 & 5 & 5 \\
\hline IC & 1 & 1 & 1 & 3 & 4 & 4 \\
\hline IDH-M & 0,50 & 1 & 1 & 2 & 3 & 3 \\
\hline IEF & 0,25 & 0,33 & 0,50 & 1 & 1 & 1 \\
\hline ID & 0,20 & 0,25 & 0,33 & 1 & 1 & 1 \\
\hline VBP & 0,20 & 0,25 & 0,33 & 1 & 1 & 1 \\
\hline
\end{tabular}

Quadro 7 - Matriz A-Fuzzy

\begin{tabular}{|c|c|c|c|c|c|c|c|c|c|c|c|c|c|c|c|c|c|c|}
\hline & A1 & A2 & A3 & B1 & B2 & B3 & $\mathrm{C} 1$ & $\mathrm{C} 2$ & $\mathrm{C} 3$ & D1 & D2 & D3 & E1 & E2 & E3 & F1 & F2 & F3 \\
\hline 1 & 0,83 & 1 & 1,25 & 0,75 & 1 & 1,25 & 1,75 & 2 & 2,25 & 0,75 & 4 & 1,25 & 3,25 & 5 & 5,25 & 4,75 & 5 & 5,25 \\
\hline 2 & 0,83 & 1 & 1,50 & 0,83 & 1 & 1,25 & 0,75 & 1 & 1,25 & 0,83 & 3 & 1,25 & 2,25 & 4 & 4,25 & 3,75 & 4 & 4,25 \\
\hline 3 & 0,45 & $\mathbf{0 , 5 0}$ & 0,58 & 0,83 & 1 & 1,50 & 0,83 & 1 & 1,25 & 0,83 & 2 & 1,50 & 1,83 & 3 & 3,25 & 2,75 & 3 & 3,25 \\
\hline 4 & 0,23 & 0,25 & 0,26 & 0,30 & $\mathbf{0 , 3 3}$ & 0,36 & 0,45 & $\mathbf{0 , 5 0}$ & 0,58 & 0,30 & 1 & 0,36 & 0,70 & 1 & 1,25 & 0,75 & 1 & 1,25 \\
\hline 5 & 0,19 & $\mathbf{0 , 2 0}$ & 0,21 & 0,23 & 0,25 & 0,26 & 0,30 & $\mathbf{0 , 3 3}$ & ,36 & 0,23 & 1 & 0,26 & 0,64 & 1 & 1,25 & 0,75 & 1 & 1,25 \\
\hline 6 & 0,19 & $\mathbf{0 , 2 0}$ & 0,21 & 0,23 & 0,25 & 0,26 & 0,30 & $\mathbf{0 , 3 3}$ & 0,36 & 0,23 & 1 & 0,26 & 0,64 & 1 & 1,50 & 0,83 & 1 & 1,25 \\
\hline
\end{tabular}

Os resultados dos pesos para as diferentes simulações são demonstrados nas equações abaixo:

$$
\begin{aligned}
& \mathrm{M} 1=0,33 \times \mathrm{IPos}+0,26 \times \mathrm{IC}+0,20 \times \mathrm{IDH} \_\mathrm{M}+0,08 \times \mathrm{IEF}+0,07 \times \mathrm{ID}+0,07 \mathrm{VBP} \text { (eq.24) } \\
& \mathrm{M} 1 \mathrm{~F}=0,23 \times \text { IPos }+0,22 \times \mathrm{IC}+0,20 \times \mathrm{IDH} \_\mathrm{M}+0,13 \times \mathrm{IEF}+0,11 \times \mathrm{ID}+0,11 \text { VBP (eq.25) } \\
& \mathrm{M} 2=0,33 \times \text { IPos }+0,20 \times \text { IC }+0,26 \times \text { IDH_M + 0,07 x IEF+ 0,07 x ID + 0,08 x VBP (eq.26) } \\
& \mathrm{M} 2 \mathrm{~F}=0,23 \times \text { IPos }+0,20 \times \text { IC }+0,22 \times \text { IDH_M + 0,13 x IEF+ 0,11 x ID + 0,11 VBP (eq.27) }
\end{aligned}
$$

A Figura 8 apresenta os mapas dos índices AHP, em intervalos igual, para os quatro modelos propostos, M1, M1F, M2 e M2F. Os modelos apresentam uma grande similaridade espacial, destacando uma região quase contínua de alta prioridade na parte norte do Estado que desce para a parte central, chegando até o sul, que acompanha as áreas de depressão, em especial a depressão do rio São Francisco (fig. 2). A utilização da lógica fuzzy não muda o padrão do modelo e a média entre os quatro índices AHP consiste em uma adequada 
representação das áreas prioritárias. As áreas prioritárias, segue preferencialmente o padrão de distribuição do índice de posses, reforçado pelas áreas de subestimativa cadastral.
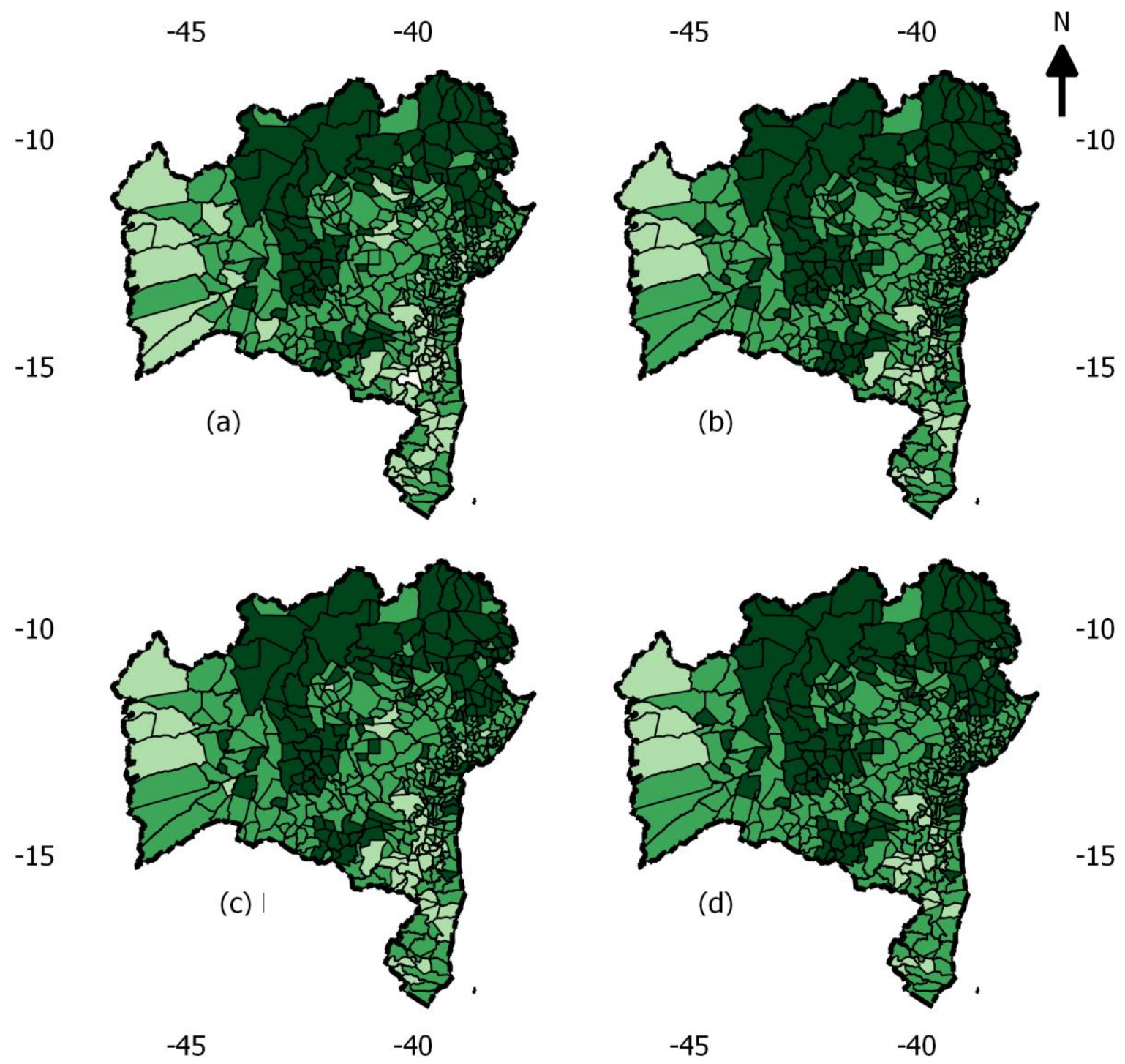

\section{Legenda}

Não Prioritária $\square$ Prioridade Baixa Prioridade Média Prioridade Alta

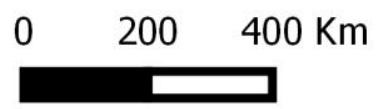

Datum: SIRGAS 2000

Fig. 8 - Cartograma dos modelos AHP: (a) M1, (b) M1F, (c) M2 e (d) M2F

O mapa do cálculo da média aritmética entre os quatro modelos evidenciou a seleção de 128 municípios com índice acima de 0,66, que são considerados como prioritários para ações imediatas de regularização fundiária e georreferenciamento no Estado da Bahia. Porém, 
fazendo o corte acima de 0,80 , obtém-se 22 municípios que podem ser considerados como Extremamente Prioritário (fig. 9).

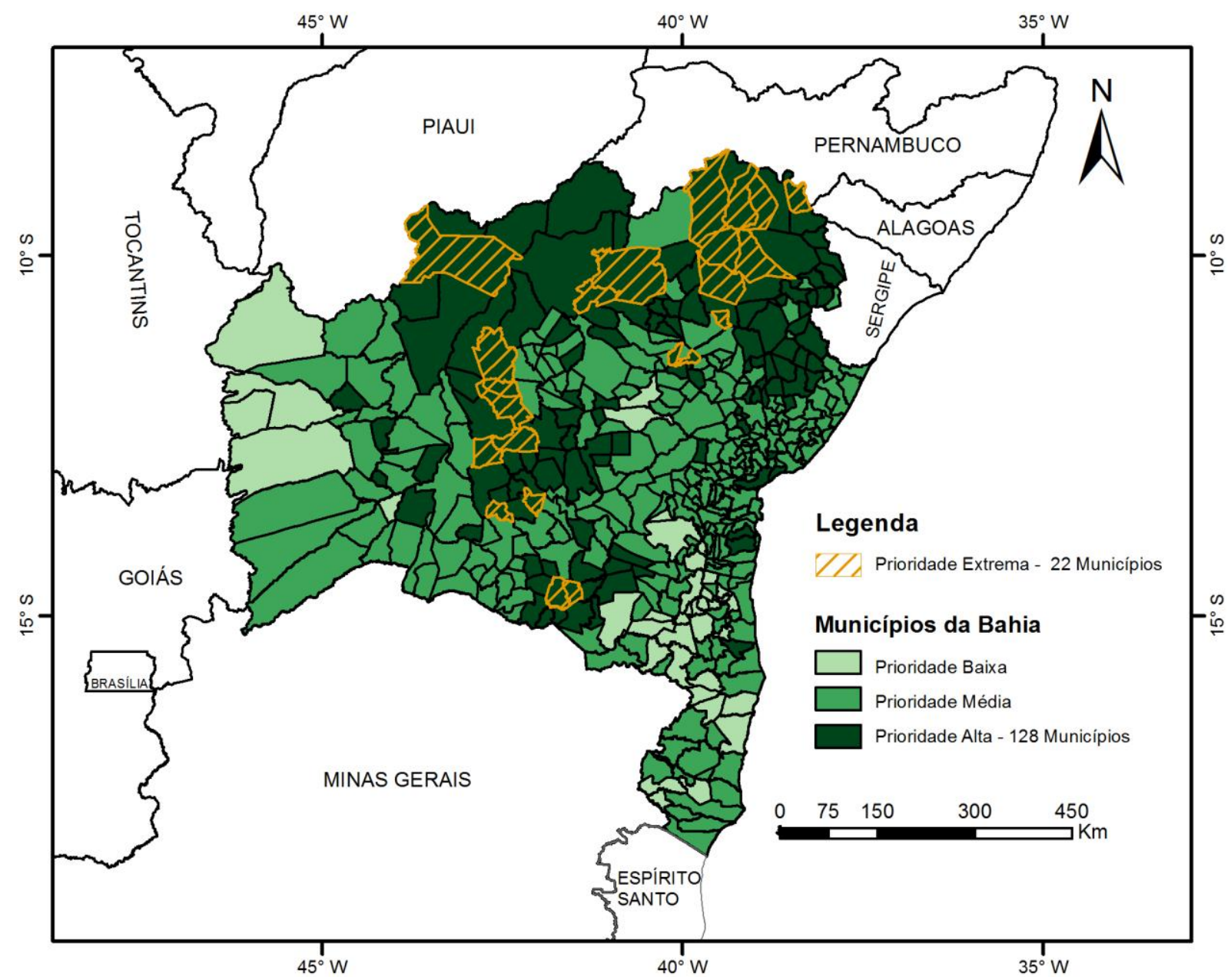

Fig. 9 - Mapa das áreas prioritárias para regularização fundiária no estado da Bahia. 


\section{CONCLUSÃO}

A grande extensão territorial do Brasil torna fundamental o desenvolvimento de metodologias espaciais para auxiliar nas ações governamentais, por exemplo a regularização fundiária. Apesar de haver muitos dados disponíveis, poucas vezes a tomada de decisão é baseada em critérios técnicos, prevalecendo o componente político ou o interesse dos movimentos sociais. Muitos assentamentos e ações de regularizações fundiárias são realizados de forma equivocada não adotando critérios de prioridade e sustentabilidade. A cultura organizacional do INCRA favorece a crença de que o agricultor sem-terra é o principal cliente do órgão. Portanto, muitas iniciativas estratégicas que deveriam ser implementadas visando o desenvolvimento rural e o aumento da produção, como a gestão e o reordenamento territorial, acabam ficando em segundo plano.

$\mathrm{O}$ avanço das geotecnologias e o aumento da disponibilidade de informações (imagens de satélites, informações espaciais dos imóveis rurais) pode renovar o sistema organizacional do Estado, estabelecendo uma melhor eficiência e racionalismo nas ações fundiárias. Nesse contexto, o Sistema de Suporte a Decisão (SSD) permite subsidiar e estabelecer critérios para priorizar a seleção de municípios para regularização fundiária, minimizando custos e focando na parcela da população mais desprovida de recursos financeiros. O SSD estabelece variáveis que podem impactar positivamente ou negativamente a solução/formulação dos problemas fundiários, bem como constrói possíveis cenários para o melhor emprego dos recursos antes da efetiva tomada de decisão. Essa prática pode melhorar a gestão territorial e ajudar a qualificação dos dados disponíveis ou sendo coletados.

A pesquisa evidência a deficiência de áreas cadastradas no Estado da Bahia dentro do SNCR. Constata-se que os agricultores em áreas com piores terrenos (menos produtivas, menor interesse comercial e em regiões com declividades fortemente ondulas e montanhosas) apresentam uma baixa taxa de cadastramento, reafirmando a sua situação de carência devido a esta situação causar limitações para a aquisição de recurso financeiros privados ou de acesso as políticas públicas. Além disso, a falta de um cadastro abrangente pode estar favorecendo a utilização de títulos falsos ou a grilagem de terras.

O emprego da AHP para a seleção de áreas prioritárias para o cadastramento fundiário é uma inovação que busca contribuir para o aprimoramento das questões da Gestão Ambiental e Territorial. O estabelecimento de áreas prioritárias para ações imediatas de regularização fundiária apenas desperta para a importância do problema fundiário para um país continental como o Brasil, que envolve entre outras coisas, revisão das leis, readequação da formação e 
do perfil profissional, estratégias de decisão, gestão territorial e cadastro de terras. 


\section{REFERÊNCIAS BIBLIOGRÁFICAS}

Akinci, H., Ozalp, A. Y. \& Turgut, B. (2013). Agricultural land use suitability analysis using GIS and AHP technique. Computers and Electronics in Agriculture, 97, 71-82. doi: 10.1016/j.compag.2013.07.006

Andrade, A. B. (2013). Base conceitual para estudos sobre a história do espaço urbano. Salvador: EdUFBA.

Bogaerts, T. \& Zevenbergen, J. (2001). Cadastral systems. Computers, Environment and Urban Systems, 25 (4), 325-337. doi: 10.1016/S0198-9715(00)00051-X

Bolloju, N. (2001). Aggregation of analytic hierarchy process models based on similarities in decision markers' preferences. European Journal of Operational Research, 128 (3), 499-508. doi: 10.1016/S0377-2217(99)00369-0

Borcard, D., Gillet, F. \& Legendre, P. (2011). Numerical ecology with R. New York: Springer.

Brasil (1964). Lei Federal 4.504. Brasil. Disponível em: <http://www.planalto.gov.br/>. Acesso em: 08 dez. 2016.

Brasil (1976). Lei Federal 6.383. Brasil. Disponível em: <http://www.planalto.gov.br/>. Acesso em: 08 dez. 2016.

Brasil (2001). Lei Federal 10.267. Brasil. Disponível em: <http://www.planalto.gov.br/>. Acesso em: 08 dez. 2016.

Brasil (2003). Lei Federal 8.629. Brasil. Disponível em: <http://www.planalto.gov.br/>. Acesso em: 08 dez. 2016.

Brasil (2006). Lei Federal 11.326. Brasil. Disponível em: <http://www.planalto.gov.br/>. Acesso em: 08 dez. 2016.

Brasil (2015). Decreto 8.447. Brasil. Disponível em: <http://www.planalto.gov.br/>. Acesso em: 08 dez. 2016.

Cassettari, C. (2015). Direito agrário. 2 ed. São Paulo: Editora Atlas S.A.

Cay, T. \& Uyan, M. (2013). Evaluation of reallocation criteria in land consolidation studies using the Analytic Hierarchy Process (AHP). Land Use Policy, 30 (1), 541-548. doi: 10.1016/j.landusepol.2012.04.023

Chan, D. Y. (1996). Application of the extend analysis method on Fuzzy AHP. European Journal of Operational Research, 95 (3), 649-655. doi:10.1016/0377-2217(95)00300-2

Chorley, R. J. \& Haggett, P. (1975). Modelos sócio-enconômicos em geografia. Rio de Janeiro: LTC.

Collins, M. G., Steiner, F. R. \& Rushman, M. (2001). Land-use suitability analysis in the united states: historical development and promising technological achievements. Environmental Management, 28 (5), 611-621. doi: 10.1007/s002670010247

Crawford, G. \& Williams, C. (1985). A note on the analysis of subjective judgment matrices. Journal of mathematical psychology, 29, 387-405. doi: 10.1016/0022-2496(85)90002-1

Deininger, K; Hilhorst, T. \& Songwe, V. (2014). Identifying and addressing land governance constraints to support intensification and land market operation: Evidence from 10 African countries. Food Policy, 48, 76-87. doi: 10.1016/j.foodpol.2014.03.003

Dias, G. O. (2007). Estado e o Agro em Tempos de Liberalização. Revista Economia e Sociologia Rural, 44 (3), 341-354. doi: 10.1590/S0103-20032006000300001 
Diez, A. G. (2011). Segredos da Bahia: Geografia. São Paulo: FTD.

Empresa Brasileira de Pesquisa Agropecuária - EMBRAPA (1979). Serviço Nacional de Levantamento e Conservação de Solos. Súmula da 10. Reunião Técnica de Levantamento de Solos. Rio de Janeiro. 83p. (Embrapa-SNLCS. Micelânea, 1).

Food and Agriculture Organization of the United Nations - FAO (1976). A Framework for Land Evaluation. FAO Soils bulletin 32, Rome: FAO. Disponível em: $<$ http://www.fao.org/docrep/X5310E/x5310e00.htm>. Acesso em: 08 dez. 2016.

Food and Agriculture Organization of the United Nations - FAO (2012). Voluntary guidelines on the responsible governance of tenure of land, fisheries and forests in the context of national food security. Rome: FAO. Disponível em: $<$ http://www.fao.org/fileadmin/user_upload/newsroom/docs/VGsennglish.pdf $>$. Acesso em: 08 dez. 2016

Friendly, M. (2002). Corrgrams: exploratory displays for correlations matrices. The American Statistician, 56 (4), 316-324. doi: 10.1198/000313002533

Gonçalves, R. S. (2009). Repensar a regularização fundiária como política de integração socioespacial. Estudos Avançados, 23 (66), 237-250. doi: 10.1590/S010340142009000200017

Graser, A. (2013). Learning QGIS 2.0. Packt Publishing Ltd.

Guedes, S. N. R. \& Reydon, B. P. (2012). Direito de propriedade de terra rural no Brasil: uma proposta institucionalista para ampliar a governança fundiária. Revista de Economia e Sociologia Rural, 50 (3): 525-544. doi: 10.1590/S0103-20032012000300008

Hartigan, J. A. (1975). Clustering algorithms. New York: Wiley.

Hartshorne, R. (1978). Propósitos e natureza da geografia. São Paulo: EdUSP.

Harvey, D. (2014). Cidade rebeldes. São Paulo: Martins Fontes.

Hasenack, M. (2013). A cartografia cadastral do Brasil. Tese (Doutorado). Programa de PósGraduação em Engenharia Civil. Universidade Federal de Santa Catarina (UFSC), Florianópolis.

Hua, Z., Gong, B. \& Xu, X. (2008). A DS-AHP approach for multi-attribute decision problem with incomplete information. Expert System with Application, 34 (3), 2221-2227. doi: 10.1016/j.eswa.2007.02.021

Instituto Brasileiro de Geografia e Estatística - IBGE (2006). Censo Agropecuário 2006. Rio de Janeiro: IBGE. Disponível em: < http://www.ibge.gov.br>. Acesso em: 12 jan. 2015.

Instituto Brasileiro de Geografia e Estatística - IBGE (2010). Estados@. Rio de Janeiro: IBGE. Disponível em: <http://www.ibge.gov.br/estadosat/perfil.php?sigla=ba $>$. Acesso em Acesso em: 08 dez. 2016.

Instituto Brasileiro de Geografia e Estatística - IBGE (2013). Produção Agrícola Municipal (PAM). Rio de Janeiro: IBGE. Disponível em: <http://www.ibge.gov.br>. Acesso em: 12 de jan. 2015.

Instituto Nacional de Colonização e Reforma Agrária - INCRA (2015). Sistema Nacional de Cadastro Rural (SNCR). Brasília: INCRA. Disponível em $<\mathrm{http}$ ://www.incra.gov.br/>. Acesso em: 05 dez. 2015. 
Jiang, H. \& Eastman, J. R. (2000). Application of fuzzy measures in multi-criteria evaluation in GIS. International Journal of Geographical Information Science, 14 (2), 173-184. doi: $10.1080 / 136588100240903$

Kaufmann, J. \& Steudler, D. (1998). Cadastre 2014 - A Vision for a Future Cadastral System. Rüdlingen and Bern, Switzerland, Report of Commission 7 Working Group 7.1, International Federation of Surveyors.

Leão, S. O. (1987). Evolução dos padrões de uso do solo agrícola na Bahia. Recife: Superintendência do Desenvolvimento do Nordeste (SUDENE).

Linhares, C. G., Gussen, C. T. G. \& Ribas, J. R. (2012). O método Fuzzy AHP aplicado à análise de riscos de usinas hidrelétricas em fase de construção. In: Congresso LatinoIberoamericano de Investigação Operacional. Anais... Rio de Janeiro, SOBRAPO. p.591-603. Disponível em: <http://www.din.uem.br/sbpo/sbpo2012/pdf/arq0185.pdf >. Acesso em: 08 dez. 2016.

Lolli, F., Ishizaka, A. \& Gamberini, R. (2014). New AHP-based approaches for multi-criteria inventory classification. International Journal of Production Economics, 156, 62-74. doi: 10.1016/j.ijpe.2014.05.015.

Medeiros, C. N. Gomes, D. D. M. \& Albuquerque, E. L. S. (2012). A concentração da posse da terra na região Nordeste e no Estado do Ceará. Geografia, Rio Claro, 37 (2), 199-220.

Michelini, C. R. (2012). Legitimidade da propriedade rural. Cuiabá: KCM Editora \& Distribuidor.

Mon, D. L., Cheng, C. H., \& Lin, J. C. (1994). Evaluating weapon system using fuzzy analytic hierarchy process based on entropy weight. Fuzzy Sets and Systems, 62 (2), 127-134. doi: 10.1016/0165-0114(94)90052-3

Mosadeghi, R., Warnken, J., Tomlinson, R. \& Mirfenderesk, H. (2015). Comparasion of Fuzzy-AHP and AHP in a spatial multi-criteria decision making model for urban land-use planning. Computers, Environment and Urban Systems, 49, 54-65, doi: /10.1016/j.compenvurbsys.2014.10.001

Murdoch, D. J. \& Chow E. D. (1996). A graphical displays of large correlations matrices. The American Statistician, 50 (2), 178-180. doi: 10.2307/2684435

Newman, C., Tarp, F. \& Broeck, K. (2015). Property rights and productivity: The case of joint land titling in Vietnam. Land Economics, 91 (1): 91-105. doi: 10.3368/le.91.1.91

Oliveira, S. N., De Carvalho Júnior, O. A., Gomes, R. A. T., Guimarães, R. F. \& Mcmanus, C. M. (2017). Deforestation analysis in protected areas and scenario simulation for structural corridors in the agricultural frontier of Western Bahia, Brazil. Land Use Policy, 61, 40-52. doi: 10.1016/j.landusepol.2016.10.046

Oliveira, S. N., De Carvalho Júnior, O. A., Gomes, R. A. T., Guimarães, R. F., \& Mcmanus, C. M. (2016) Landscape-fragmentation change due to recent agricultural expansion in the Brazilian Savanna, Western Bahia, Brazil. Regional Environmental Change, 1-13. doi: 10.1007/s10113-016-0960-0

Pacheco, M. A. C. \& Vellasco, M. M. B. R. (2007). Sistemas Inteligentes de Apoio à Decisão. Rio de Janeiro: Editora PUC Rio.

Programa das Nações Unidas para o Desenvolvimento - PNUD (2010). Atlas do Desenvolvimento Humano no Brasil. Disponível em: <http://www.atlasbrasil.org.br/2013/pt/o_atlas/idhm/>. Acesso em: 08 dez. 2016. 
Pochmann, M. (2015). Desigualdade econômica no Brasil. São Paulo: Editora Ideias e Letras.

Rambo, L. I. (2005). Uma proposta para conexão do Registro de Imóveis ao Cadastro Imobiliário Urbano. 220 p. Tese (Doutorado em Engenharia Civil). Universidade Federal de Santa Catarina, Florianópolis.

Rezende, G. C. \& Guedes, S. N. R. (2008). Formação histórica dos direitos de propriedade da terra no Brasil e nos Estados Unidos e a sua relação com as políticas agrícolas atualmente adotadas nesses dois países. In: COELHO, A. B., TEIXEIRA, E. C. \& BRAGA, M. J. (org.), Recursos naturais e crescimento econômico (pp. 279-311). Editora da Universidade Federal de Viçosa, Brasil.

Saaty, R. W. (1987). The analytic hierarchy process-what it is and how it is used. Mathematical Modelling, 9 (3), 161-176. doi: 10.1016/0270-0255(87)90473-8

Saaty, T. L. \& Zoffer, H. J. (2012). Nina`s decision: how to make better decisions and resolve conflicts. International Journal of the Analytic Hierarchy Process, 4 (1), 78-86. doi: 10.13033/ijahp.v4i1.139

Saaty, T. L. (1980). The Analytic Hierarchy Process. New York: McGraw Hill International.

Saaty, T. L. (2008). Decision making with the analytic hierarchy process. International Journal of Services Sciences, 1 (1), 83-98. doi: 10.1504/IJSSci.2008.01759

Salomon, V. P., Montevechi, J. A. \& Pamplona, E. O. (1999). Justificativas para aplicação do método de análise hierárquica. In: Encontro Nacional de Engenharia de Produção, 19., Anais... Rio de Janeiro. 17p. Disponível em: < http://www.iepg.unifei.edu.br/edson/download/Artahp99.pdf>. Acesso em: 08 dez. 2016

Schier, R. A. (2003). Trajetórias do conceito de paisagem na geografia. RA'E GA - O Espaço Geográfico em Análise, 7, 79-85. doi: 10.5380/raega.v7i0.3353

Serviço Geológico do Brasil - CPRM (2016). Mapa de declividade em percentual do relevo brasileiro. Brasília: CPRM. Disponível em: <http://www.cprm.gov.br/>. Acesso em: 12 jan. 2015.

Shannon, C. (1949). Communication Theory of Secrecy Systems. Bell System Technical Journal, 28 (4), 656-715. doi: 10.1002/j.1538-7305.1949.tb00928.x

Silva, A. N. R. D., Ramos, R. A., Souza, L. C. L., Rodrigues, D. S. \& Mendes, J. F. (2004). SIG: uma plataforma para introdução de técnicas emergentes no planejamento urbano, regional e de transportes. São Carlos: Ed. dos Autores. Disponível em: $<$ http://repositorium.sdum.uminho.pt/bitstream/1822/2331/1/Pages\%20from\%20LivroBrasil.p df>. Acesso em: 08 dez. 2016

Smyth, A. J. \& Dumanski, J. (1993). FESLM: An international framework for evaluating sustainable land management. Rome: FAO. Disponível em: $<$ http://www.fao.org/docrep/T1079E/t1079e00.htm>. Acesso em: 08 dez. 2016.

Soto, H. (2001). O mistério do capital. Rio de Janeiro: Editora Record.

Souza, E. J. C. (2008). Políticas Territoriais do Estado da Bahia: Regionalização e Planejamento. Dissertação (Mestrado em Geografia). 158 p. Universidade Federal da Bahia, Salvador.

Uyan, M. (2013). GIS-based solar farms site selection using analytic hierarchy process (AHP) in Karapinar region, Konya/Turkey. Renewable and Sustainable Energy Reviews, 28, 1-17. doi: 10.1016/j.rser.2013.07.042 
Van Zyl, J. J. (2001). The Shuttle Radar Topography Mission (SRTM): a breakthrough in remote sensing of topography. Acta Astronautica, 48 (5), 559-565. doi: 10.1016/S00945765(01)00020-0

Wang, Y. M. \& Elhag, T. M. S. (2006). An approach to avoiding rank reversal in AHP. Decision Support System, 42 (3), 1474-80. doi: 10.1016/j.dss.2005.12.002 